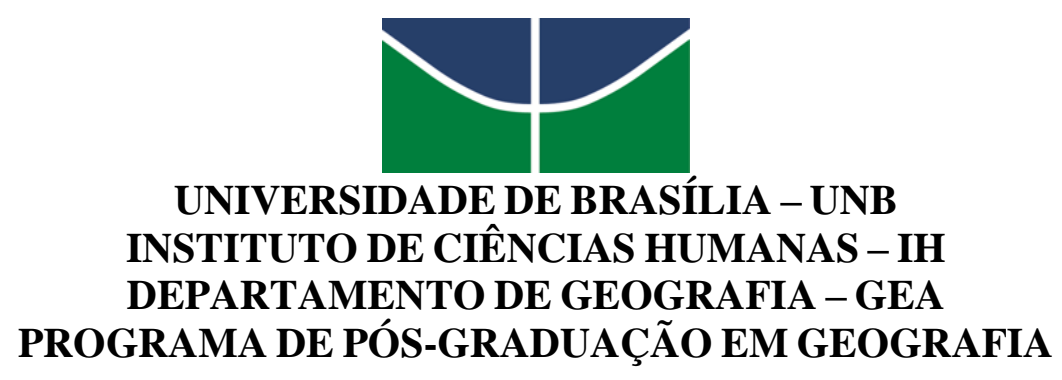

Mapeamento de áreas queimadas usando séries temporais normalizadas derivadas de dados NBR-MODIS durante o período 2001-2014 no Parque Nacional das Emas.

Mapping burned areas using standardized time series derived from NBR-MODIS data during the period 2001-2014 in the Emas National Park.

Dissertação de Mestrado

Jonathan Vinagre Braga

Matrícula: 13/0073318

Orientador: Osmar Abílio de Carvalho Júnior 


\title{
MAPEAMENTO DE ÁREAS QUEIMADAS USANDO SÉRIES TEMPORAIS NORMALIZADAS DERIVADAS DE DADOS NBR-MODIS DURANTE O PERÍODO 2001-2014 NO PARQUE NACIONAL DAS EMAS.
}

\author{
Jonathan Vinagre Braga
}

Dissertação de Mestrado submetida ao Departamento de Geografia da Universidade de Brasília, como parte dos requisitos necessários para a obtenção do Grau de Mestre em Geografia, área de concentração Geoprocessamento, opção Acadêmica.

Aprovado por:

Osmar Abílio de Carvalho Júnior, Doutor (Universidade de Brasília-UnB)

(Orientador)

Heloísa Sinátora Miranda, Doutora (Universidade de Brasília-UnB)

(Examinador Externo)

Alfredo da Costa Pereira Júnior, Doutor (Instituto Nacional de Pesquisas EspaciaisINPE)

(Examinador Externo)

Brasília-DF, Dezembro de 2015. 
Vinagre, Jonathan

Mapeamento de Áreas Queimadas usando Séries Temporais Normalizadas Derivadas de Dados NBR-MODIS Durante o Período 2001-2014 no Parque Nacional das Emas.

Dissertação de Mestrado - Universidade de Brasília. Departamento de Geografia

1. Fogo

2. MODIS

3. Cerrado

4. Sensoriamento Remoto

5. Unidades de Conservação

I. UnB-GEA

II. Mestrado

É cedida a Universidade de Brasília permissão para reproduzir cópias desta dissertação e emprestar ou vender tais cópias somente para propósitos acadêmicos e científicos. $\mathrm{O}$ autor reserva outros direitos de publicação e nenhuma parte desta dissertação de mestrado pode ser reproduzida sem a permissão do autor.

Jonathan Vinagre Braga 


\section{AGRADECIMENTOS}

Primeiro a Deus, por toda benção, proteção e companhia de cada dia.

Agradeço minha mãe, Mariângela Vinagre, orgulho da minha vida, que é responsável por quem me tornei. Sem ela não teria chegado até aqui. Amo-te infinitamente mãe.

À minha tia Maria do Carmo, tio Batista e Joaquim, de importância fundamental para minha educação.

Ao meu pai, Sandro Almeida Braga, que está e sempre estará presente em meus pensamentos e em meu coração. Também aos meus irmãos mais novos, Lucas e Malú.

Agradeço aos meus irmãos mais velhos, Júnior e Fê, por todos os conselhos, discussões e estímulos, que eu soube aproveitar bem. Sem esquecer também do fato de terem me dado os sobrinhos mais lindos e especiais do mundo: Amanda; Arthur; Ana Luíza (Nunuu) e Rafa. Que todas às vezes garantiram minha alegria nos meus curtos períodos em São Paulo.

Agradeço ao meu primo/irmão Alex, por todas as piadas, risadas e companheirismo, que certamente me deram mais ânimo para enfrentar os obstáculos dessa jornada.

Ao Tio Ricardo e Tia Meire, que sempre me incentivaram e ensinaram a importância de uma boa educação.

Ao Xúnior, Pablo, Bruce, Adam, Bárbara, Vítors (Paiva e Soares), Victors (Gontijo e Vogado), Lalá, Liara, Clara Angeleas, Ana Karinna, Carlinha, Gabriel Daldegan, Matheus, Gabriel Ramos e tantos outros, que certamente fazem minha vida muito mais completa.

À Rayana, por todas as conversas, risadas e retrospectivas que, com certeza, fizeram das minhas pausas para descanso muito mais divertidas.

Aos amigos que fiz na TNC, Lícia Maria, Arley, Fernando, Adolfo, Barnes, Carol, Karen, Ayla, e Grazi, por todo aprendizado profissional e pessoal que pude desenvolver com vocês.

Aos professores Roberto Trancoso e Renato Guimarães, por todas as contribuições e críticas no processo de construção desse trabalho.

Ao professor e orientador Osmar Abílio, pela paciência, incentivo e confiança, além de todas as contribuições essenciais para esse trabalho.

Aos Chainsaw Ricardo, Rebecca e Feliciano, por todas as horas de estudo, revisões, conversas, risadas, desesperos compartilhados e, claro, por todo suporte. Vocês fizeram toda a diferença nesse processo.

\section{Muito Obrigado!}




\section{SUMÁRIO}

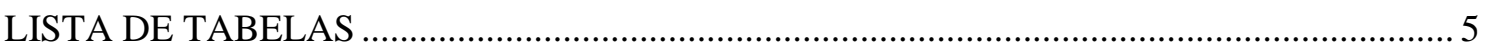

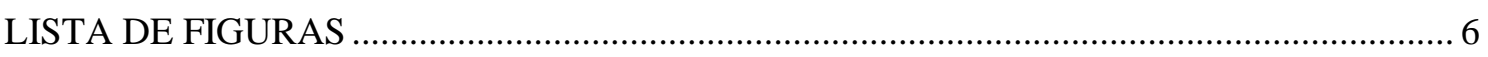

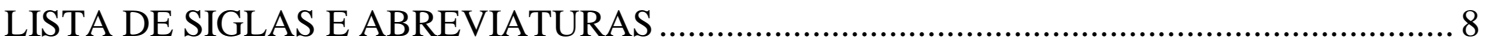

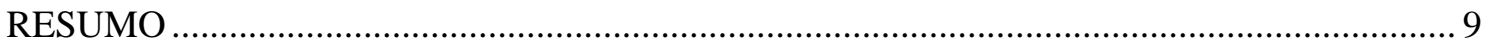

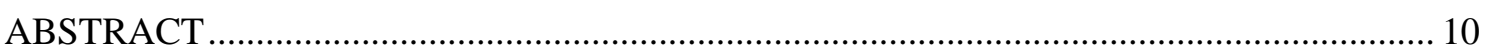

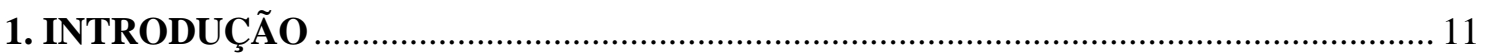

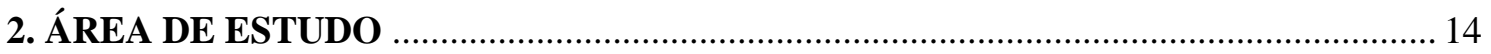

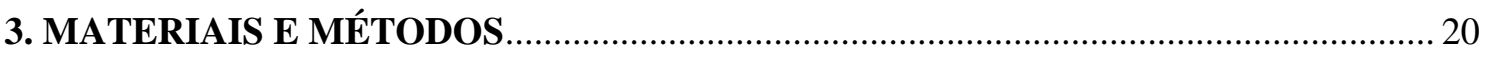

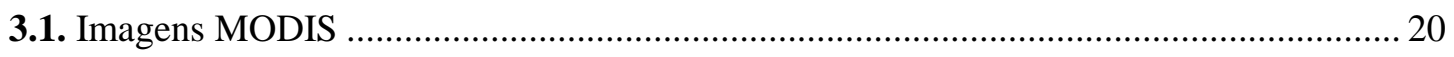

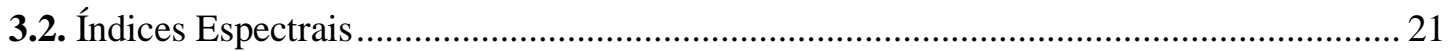

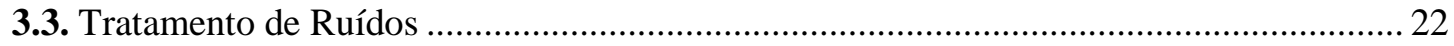

3.4. Normalização pela Média das assinaturas temporais e a deteç̧ão das áreas queimadas . 23

3.5. Análise comparativa com sensores de mais alta resolução espacial (TM-LANDSAT-5,

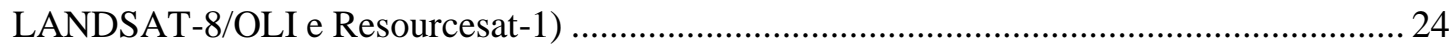

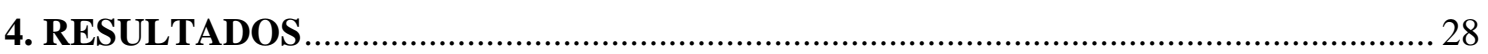

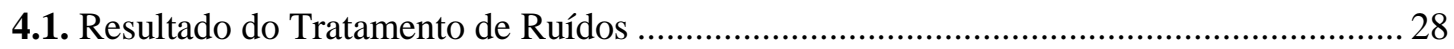

4.2. Detecção das Áreas Queimadas a partir de Séries Temporais Normalizadas pela Média 29

4.3. Resultado das Queimadas Anuais no Período 2001-2014 Utilizando os Índices

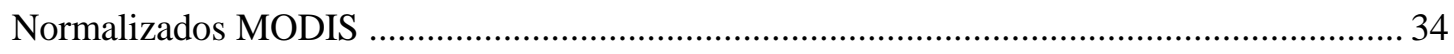

4.4. Resultado das Queimadas entre 2001 e 2014 (Base Referência) ...................................... 37

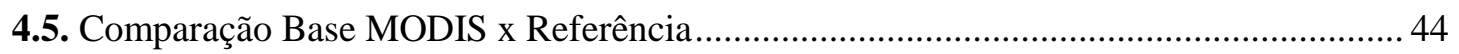

5. DISCUSSÃO

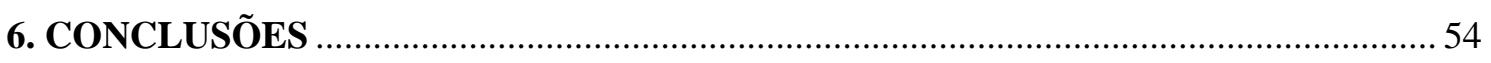

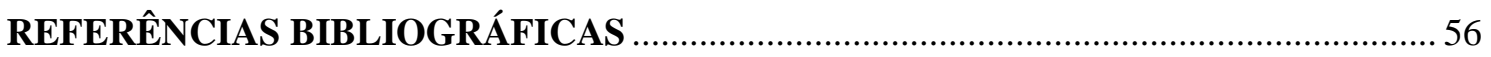




\section{LISTA DE TABELAS}

Tabela 1. Imagens utilizadas para o mapeamento das cicatrizes de fogo ao longo o período 2001-2014.

Tabela 2. Área de queimada anual no Parque Nacional das Emas no período 2001-2014 utilizando séries temporais nmNBR-MODIS.

Tabela 3. Áreas com recorrência dos eventos de queimadas no Parque Nacional das Emas no período 2001-2014 utilizando séries temporais nmNBR-MODIS

Tabela 4. Área de queimada anual no Parque Nacional das Emas no período 2001-2014 utilizando imagens temporais dos sensores TM-LANDSAT 5, LANDSAT-8/OLI e Resourcesat.

Tabela 5. Áreas com recorrência anual dos eventos de queimadas no Parque Nacional das Emas no período 2007-2014 utilizando imagens temporais dos sensores TMLANDSAT 5 LANDSAT-8/OLI e Resourcesat........................................................ 41

Tabela 6. Distribuição temporal dos focos de incêndio do Parque Nacional das Emas considerando as imagens temporais dos sensores TM-LANDSAT 5 LANDSAT-8/OLI e

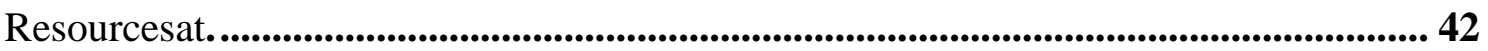

Tabela 7. Coeficientes de acurária para cada ano. Comparação base MODIS e LANDSAT/Resoucesat. ................................................................................................5 5 


\section{LISTA DE FIGURAS}

Figura 1. Mapa de localização do Parque Nacional das Emas. (LANDSAT 8 OLI, 23/09/2014, 4R5G6B).

Figura 2. Gráfico da média histórica da precipitação mensal (mm) (Fonte: ANA, Estação Costa Rica - MS)

Figura 3. Mapa de vegetação e aceiros no Parque Nacional das Emas. Fonte: adaptado de Ramos Neto (2000).

Figura 4. Representação do cubo 3D temporal de imagens do sensor MODIS. 21

Figura 5. Somatório para agrupamento das cicatrizes de queimadas por ano.

Figura 6. Comparação entre a série temporal NBR original (curva vermelha), a filtragem Savitzky-Golay com polinômio 5 (curva azul), S-G com polinômio 7 (curva verde) e SG com polinômio 9 (curva preta).

Figura 7. Comparação entre a série temporal NBR original (curva vermelha), a filtragem Savitzky-Golay com polinômio 5 e limite igual a 0,09 para eliminação dos ruídos de impulso (curva azul), e S-G com mesmo polinômio e sem limite de corte para a suavização (curva verde).

Figura 8. Comparação entra as imagens a) NBR original e b) nmNBR no ano de 2007.

Figura 9. Comparação entre as séries temporais NBR (a) e nmNBR (b). Destaque para a normalização da feição de fogo.

Figura 10. Classificação usada como imagem-verdade na determinação do limiar ótimo (a) e imagem normalizada (nmNBR) utilizada na comparação (b), ano 2005.

Figura 11. Classificação usada como imagem-verdade na determinação do limiar ótimo (a) e imagem normalizada (nmNBR) utilizada na comparação (b), ano 2010.

Figura 12. Classificação usada como imagem-verdade na determinação do limiar ótimo (a) e imagem normalizada (nmNBR) utilizada na comparação (b), ano 2014.

Figura 13. Curvas dos valores do coeficiente Kappa (a) e Overall (b) considerando diferentes valores limites de corte da imagem nmNBR do dia 2005/257.

Figura 14. Curvas dos valores do coeficiente Kappa (a) e Overall (b) considerando diferentes valores limites de corte da imagem nmNBR do dia 2010/241.

Figura 15. Curvas dos valores do coeficiente Kappa (a) e Overall (b) considerando diferentes valores limites de corte da imagem nmNBR do dia 2014/281. 
Figura 16. Mapa das ocorrências anuais de queimadas para o Parque Nacional das Emas utilizando séries temporais nmNBR-MODIS.

Figura 17. Classificação dos meses de ocorrência de áreas queimadas (2001 - 2004). 38

Figura 18. Classificação dos meses de ocorrência de áreas queimadas (2005 - 2008). 39

Figura 19. Classificação dos meses de ocorrência de áreas queimadas (2009 - 2012). 40

Figura 20. Classificação dos meses de ocorrência de áreas queimadas (2013 - 2014). 41

Figura 21. Mapa das ocorrências anuais de queimadas para o Parque Nacional das Emas utilizando imagens temporais dos sensores TM-LANDSAT 5 LANDSAT-8/OLI e Resourcesat

Figura 22. Histórico de queimadas do PNE. Fonte dos dados até 2003 - França et al. (2007).

Figura 23. Sequência de imagens MODIS evidenciando áreas queimadas não mapeadas na base de referência por indiponibilidade de imagens LANDSAT ou Resourcesat. .... 46

Figura 24. Áreas queimadas não mapeadas na base de referência por excessiva cobertura de nuvens.

Figura 25. Comparação das recorrências anuais de queimadas no interior do PNE. Mapeamentos MODIS e LANDSAT/Resourcesat - Anos 2001 a 2008.

Figura 26. Comparação das recorrências anuais de queimadas no interior do PNE. Mapeamentos MODIS e LANDSAT/Resourcesat - Anos 2009 a 2014

Figura 27. Comparação dos somatórios de áreas queimadas no interior do PNE. Base de referência (a) e base MODIS (b). 50 


\section{LISTA DE SIGLAS E ABREVIATURAS}

ANA - Agência Nacional de Águas

AVHRR - Advanced Very Resolution Radiometer

AWiFS - Advanced Wide Field Sensor

$\mathrm{dNBR}$ - NBR difference

dNDVI - NDVI difference

GOES - Geostationary Operational Environmental Satellite

IBAMA - Instituto Brasileiro do Meio Ambiente e dos Recursos Naturais Renováveis

ICMBio - Instituto Chico Mendes de Conservação da Biodiversidade

INPE - Instituto Nacional de Pesquisas Espaciais

LISS - Linear Imaging Self Scanner

MODIS - Moderate Resolution Imaging Spectroradiometer

NASA - National Aeronautics and Space Administration

NBR - Normalized Burn Ratio

NDVI - Normalized Difference Vegetation Index

NIR - Near Infrared

nmNBR - NBR normalizado pela Média

OLI - Operational Land Imager

PNE - Parque Nacional das Emas

S-G - Savitzky - Golay

SPOT - Satellite Pour l Observation de la Terre

SWIR - Short Wave Infrared

TIRS - Thermal Infrared Sensor

TM - Thematic Mapper

UNESCO - Programa das Nações Unidas para a Educação, a Ciência e a Cultura

(United Nations Educational, Scientific and Cultural Organization)

USGS - Serviço Geológico dos Estados Unidos (United States Geological Survey) 


\section{RESUMO}

O presente trabalho tem como objetivo realizar o mapeamento das ocorrências de queimadas no interior do Parque Nacional das Emas utilizando séries temporais normalizadas NBR-MODIS no período 2001-2014. A metodologia pode ser subdivida nas seguintes etapas: (a) cálculo do índice NBR, (b) tratamento de ruído, (c) normalização das séries temporais NBR-MODIS (nmNBR-MODIS), (d) definição do valor limite para aplicação nas imagens nmNBR-MODIS gerando as máscara dos eventos de fogo, (e) aglutinação dos eventos de fogo em dados anuais, (d) comparação com eventos de fogo anuais obtidos a partir da interpretação visual de imagens LANDSAT e Resourcesat. O filtro Savitzky-Golay foi utilizado para a eliminação dos ruídos e suavização das séries temporais NBR-MODIS. Este filtro foi adequado no mapeamento de queimadas, pois garantiu a preservação de picos negativos nas séries temporais, que normalmente estão associados às ocorrências de fogo. As séries temporais NBR-MODIS foram normalizadas pelo Média (nmNBR-MODIS), possibilitando a definição de um único valor limite para extração de áreas queimadas em diferentes fitofisionomias do Cerrado. A definição do melhor valor limite foi realizada de forma automática, definindo o melhor valor limite a partir dos maiores coeficientes Kappa e Overall em comparação a uma classificação por interpretação visual de imagens LANDSAT e Resourcesat. O valor limite é aplicado para toda a série temporal nmNBR-MODIS gerando uma série temporal de máscaras de áreas queimadas. Os eventos de fogo das séries temporais MODIS foram aglutinados em dados anuais e comparados com uma base de dados provenientes da interpretação visual de imagens LANDSAT e Resourcesat. Os dados obtidos entre as duas técnicas mostraram uma grande similaridade as principais divergências foram as seguintes: (a) superestimava das séries temporais MODIS devido ao mapeamento errôneo de eventos de fogo com áreas úmidas próximas aos cursos d'água que apresentam queda no índice nmNBRMODIS; e (b) subestimativa da classificação visual devido a falta de dados provenientes da cobertura de nuvens e grandes intervalos sem recobrimento de imagens. O método descrito evidencia um grande potencial para o monitoramento de eventos de fogo no bioma Cerrado. 


\begin{abstract}
This paper aims to map the fire occurrences within the Emas National Park using standardized NBR-MODIS time series in the period 2001-2014. The methodology can be divided into the following steps: (a) NBR index calculation; (b) noise treatment; (c) standardization of NBR-MODIS time series (nmNBR-MODIS); (d) definition of the threshold value for burned area detection in nmNBR-MODIS, (e) agglutination of fire events on annual data, (d) comparison with annual fire events obtained from the visual interpretation of Landsat and ResourceSat images. The Savitzky-Golay filter was applied for noise removal and smoothing of NBR-MODIS time series. This filter is suitable for mapping burned as it ensures the preservation of negative peaks in time series, which are normally associated with fire occurrences. The NBR-MODIS time series were normalized by the Mean data (nmNBR-MODIS), enabling the definition of a single threshold value for extraction of burned areas in different vegetation types of the Cerrado. The definition of the best threshold was performed automatically by setting the best value limit from higher Kappa and Overall coefficients compared to a classification by visual interpretation of Landsat and ResourceSat images. The results between the two techniques show great similarity. However, there were some differences: (a) overestimated the nmNBR-MODIS time series due to improper fire event mapping on wetlands near the waterways, which have a decline in the nmNBR-MODIS values; and (b) underestimation of visual classification due to lack of data from the cloud cover and long intervals without images. The described method shows great potential for monitoring of fire events in the Cerrado biome.
\end{abstract}




\section{INTRODUÇÃOO}

O bioma Cerrado abrange uma vasta área do território brasileiro, ocupando aproximadamente 208 milhões de hectares (SANO et al., 2001), que corresponde a um quinto do país, inferior apenas em extensão para o bioma Amazônico (RATTER. et al., 1997). O Cerrado é a savana de maior diversidade do mundo, ocorrendo em diversos tipos de solos e formações geológicas (EITEN, 1972). Diversas fitofisionomias compõe este bioma: Cerradão, Cerrado Sentido Restrito, Campo Cerrado, Campo Sujo, Campo Limpo, Matas de Galeria e Buritizais (EITEN, 1985).

O fogo já estava presente no Cerrado mesmo antes da ocupação do homem. Este fenômeno altera a estrutura da vegetação, as características da composição do solo e os ciclos da água e carbono (ARAÚJO et al., 2012). A ocorrência de queimadas pode provocar perda de matéria orgânica do solo (JAISWAL et al., 2002). Além disso, as queimadas têm grande contribuição na emissão de gases estufa. No Brasil, apesar da utilização de combustíveis fósseis terem impacto no percentual de gases estufa emitido, a principal fonte está relacionada às queimadas provenientes do desmatamento (CERRI et al., 2009).

Os fatores envolvidos na ocorrência e propagação de um evento de queimada são diversos, tais como a frequência de raios, altas temperaturas, duração do período seco e ventos intensos (ARAÚJO et al., 2012). São consideradas três causas principais para a ocorrência do fogo: naturais, pela incidência de raios; antrópicos de origem acidental; e antrópicos de origem intencional (JAISWAL et al., 2002). Embora a ocorrência de incêndios naturais seja comum no Cerrado (MIRANDA et al., 2002), atualmente a quase totalidade dos eventos de fogo é em decorrência da ação antrópica, seja acidental ou intencionalmente (FRANÇA \& RIBEIRO, 2008). No Cerrado, grande parte das queimadas está fortemente relacionada ao desmatamento, preparação do solo para agricultura e na pecuária como estímulo a rebrota da vegetação que serve como alimentação de gado, principalmente na estação seca (PIVELLO \& COUTINHO, 1992). Embora algumas espécies desse bioma estejam adaptadas aos eventos de fogo, a alta recorrência de queimadas pode gerar alguns impactos negativos (DIAS, 2006), podendo causar mudanças na florística e na estrutura da vegetação e até mesmo alterar a densidade de árvores e arbustos (MEDEIROS \& MIRANDA, 2005). Como recentemente a frequência de queimadas tem aumentado significativamente (GOMES et al., 2014), os estudos sobre fogo se tornam relevantes para a avaliação da cobertura vegetal de Cerrado. 
O sensoriamento remoto é uma importante ferramenta para o estabelecimento de um sistema de monitoramento do bioma Cerrado, incluindo os eventos de queimada (DALDEGAN et al., 2014.; CARVALHO JUNIOR et al., 2009). O monitoramento contínuo da vegetação tem sido obtido pelo uso de séries temporais de sensores com alta resolução temporal, tais como: System Pour l'Observation de la Terre (SPOTVEGETATION), Advanced Very High Resolution Radiometer (AVHRR), Geostationary Operational Environmental Satellite (GOES) e Moderate Resolution Imaging Spectroradiometer (MODIS) (SILVA et al., 2005; SCHROEDER et al., 2008; WARDLOW \& EGBERT, 2008; ZHANG, 2015).

Os estudos de sensoriamento remoto para o mapeamento do fogo focam na identificação da variação de emissão de energia detectada no momento da combustão ou no mapeamento das cicatrizes de queimadas a partir da diferenciação da resposta espectral (GIGLIO et al., 2006; ALMEIDA FILHO \& SHIMABUKURO, 2004). Na identificação das áreas queimadas, a técnica mais utilizada combina duas operações algébricas: índice espectral e diferença sazonal entre as imagens de pré- e pós-fogo. Portanto, muitas pesquisas recaem na avaliação de bandas e geração de índices espectrais para uma melhor distinção dos eventos de fogo (CHUVIECO, 1999; LIBONATI, 2010; DIAZ-DELGADO et al., 2003, FANG \& YANG, 2014). Diferentes índices têm sido testados e propostos, no entanto os mais difundidos são: Normalized Difference Vegetation Index (NDVI) (ROUSE et al., 1974) e Normalized Burn Ratio (NBR) (KEY \& BENSON, 1999). Diversas pesquisas realizam comparações entre os diferentes índices presentes na literatura na capacidade de identificar áreas queimadas (EPTING et al., 2005, KINOSHITA \& HOGUE, 2011, KOBAYASHI \& DYE, 2005, VERAVERBEKE et al., 2010; 2011; VERBESSELT et al., 2006).

A diferença sazonal é uma das técnicas mais simples para a detecção de mudança em imagens bi-temporais (COPPIN et al., 2004) e têm sido frequentemente utilizada no mapeamento do fogo a partir de índices espectrais. A combinação das duas técnicas gera, por exemplo, os índices: dNDVI (KASISCHKE et al., 1993) e dNBR (KEY \& BENSON, 1999). Cabe salientar que outras técnicas de detecção de mudanças também têm sido avaliadas e propostas na análise de áreas queimadas, tais como as baseadas em redes neurais e change vector analysis (CHUVIECO et al., 2008; PETROPOULOS et al., 2010; MAEDA et al., 2011). 
No entanto, a aplicação da técnica de diferenças sazonais em séries temporais longas apresentam fortes limitações por causa do aumento da presença de ruídos e pela confusão com outras feições que não são provenientes de fogo (DE CARVALHO JÚNIOR et al., 2015, LOBODA et al., 2007, VERAVERBEKE et al., 2010). Por exemplo, as diferenças interanuais no início da produção de folhas (greenup) e senescência podem causar feições similares e não correlacionados a áreas queimadas (VAN WAGTENDONK et al., 2004). A grande vantagem na análise bi-temporal é a possibilidade de uma seleção minuciosa das imagens que minimize os efeitos adversos, sendo inviável para uma série temporal longa. Com o propósito de realçar as feições de queima e evitar os efeitos indesejáveis da diferença sazonal foi proposto o método de normalização pela Média das séries temporais.

O presente trabalho possui como objetivo realizar o mapeamento das ocorrências de queimadas dentro do Parque Nacional das Emas (PNE) por meio da utilização séries temporais do sensor MODIS em um período de 14 anos. Na detecção das áreas queimadas são comparados os índices espectrais normalizados pela Média do índice NBR (nmNBR) com as classificações visuais a partir de outros sensores de melhor resolução espacial (TM-Landsat 5, Landsat 8- OLI e Resourcesat) para a verificação da acurácia. 


\section{2. ÁREA DE ESTUDO}

A área de estudo compreende a região do Parque Nacional das Emas- PNE (Figura 1), limitado pelas coordenadas 17 $51^{\prime} 41^{\prime \prime}$ e $18^{\circ} 20^{\prime} 57^{\prime \prime}$ de latitude Sul e $53^{\circ} 06^{\prime} 56^{\prime}$ ' e 52 $44^{\prime} 20^{\prime \prime} \mathrm{W}$ de longitude Oeste, cobrindo parte dos municípios de Mineiros e Chapadão do Céu, no Estado de Goiás e Costa Rica, no Estado do Mato Grosso do Sul. O limite oeste do parque está sobre o divisor das bacias do rio Prata e Amazônica.

A criação do parque foi em 1961 através do decreto 49.874 de 11 de janeiro de 1961 e possui área aproximada de 132.800 hectares sendo uma das maiores unidades de conservação no Cerrado brasileiro administrada pelo ICMBio. O parque entrou na lista de patrimônio natural mundial da UNESCO a partir de 2001 devido a sua importância para o bioma Cerrado, contendo vários mamíferos pequenos e raros e espécies de aves que não ocorrem em outras partes do Cerrado (UNESCO, 2001).
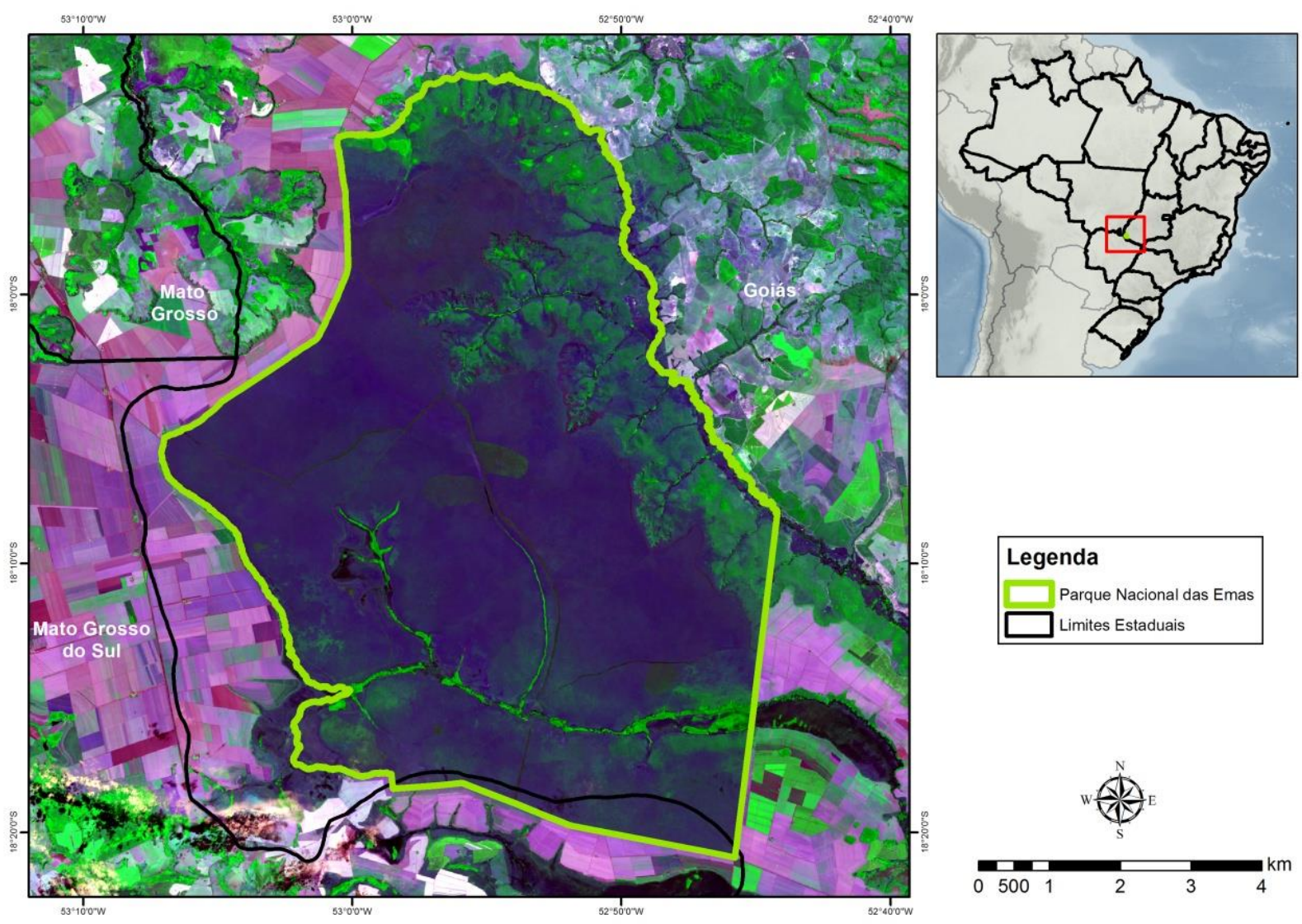

Figura 1. Mapa de localização do Parque Nacional das Emas. (LANDSAT 8 OLI, 23/09/2014, 4R5G6B).

A precipitação média anual no parque fica em torno de $1.600 \mathrm{~mm}$, com regime típico de ambiente tropical, onde os volumes máximos ocorrem no verão e os mínimos no inverno. A precipitação total anual apresenta uma concentração de $90 \%$ nos meses de 
outubro a abril (Figura 2). O inverno é seco, podendo durar cinco meses, indo normalmente de maio a setembro (IBAMA, 2004). A temperatura média anual fica em torno de $22.5^{\circ} \mathrm{C}$. Entre os meses de outubro e dezembro são registradas as temperaturas médias mais elevadas do ano, em torno de $25^{\circ} \mathrm{C}$. Já as mais baixas ocorrem no mês de junho, onde os registros marcam em torno de $10^{\circ} \mathrm{C}$ (IBAMA, 2004).

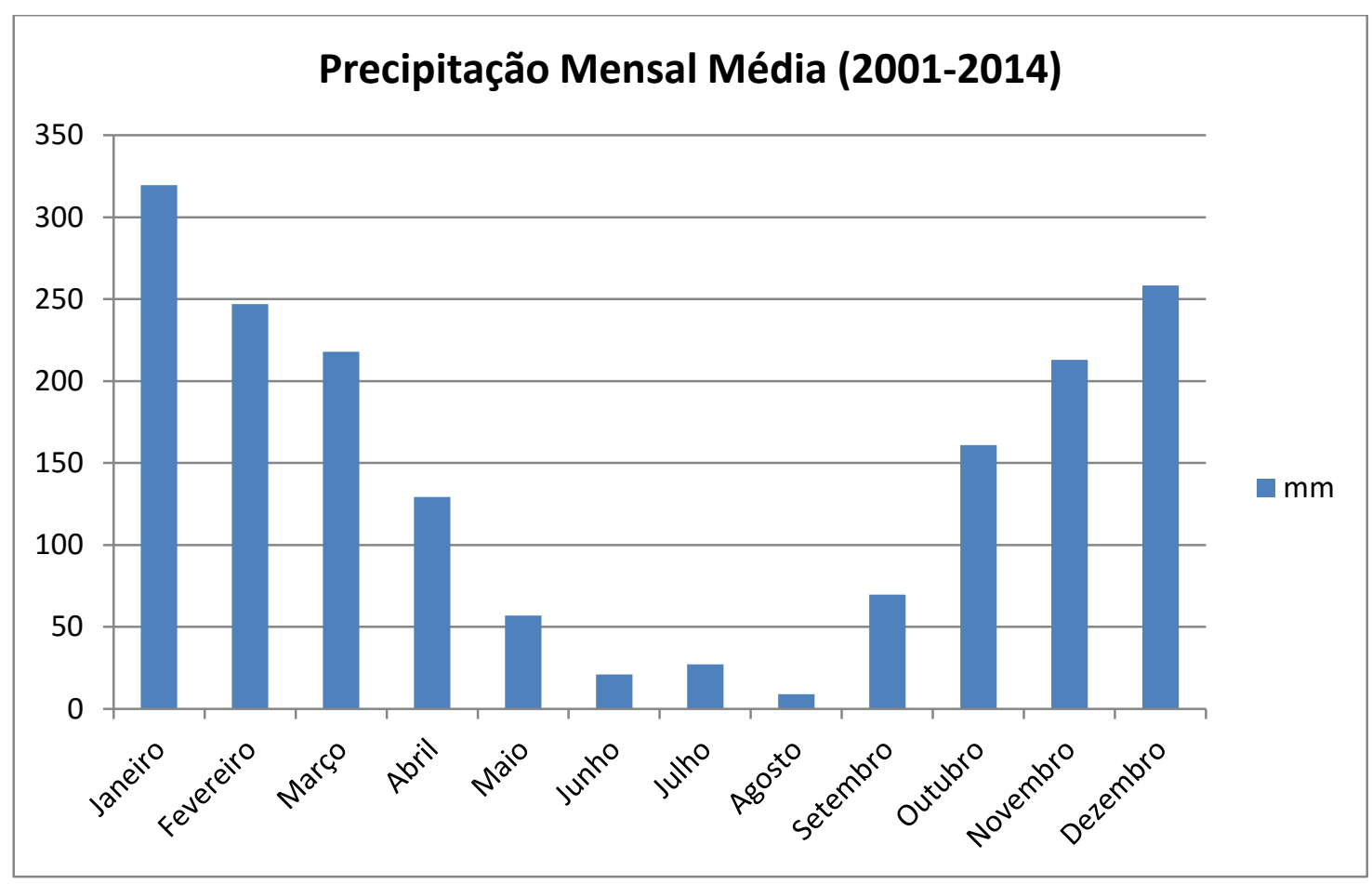

Figura 2. Gráfico da média histórica da precipitação mensal (mm) (Fonte: ANA, Estação Costa Rica - MS)

O PNE apresenta como formações geológicas os arenitos do Grupo Bauru, da Formação Adamantina (SOARES et al., 1980). Bancos de arenitos com estratificação cruzada e arenitos lamíticos são alguns exemplos de rochas encontradas nessa formação (PAULA \& SILVA et al., 2003). Tais rochas são mais encontradas na porção nordeste do parque, devido ao entalhamento do vale do Rio Jacuba (IBAMA, 2004). Nas zonas em que o entalhamento dos rios, principalmente Jacuba e Formoso, são mais expressivos, são encontrados também basaltos da Formação Serra Geral, além de aluviões recentes (IBAMA, 2004).

O parque localiza-se na região do Planalto Central, sendo constituídas principalmente por extensas chapadas com relevo suave, altitudes entre 800 e 900m e predomínio de Latossolos (Latossolo Vermelho-Escuro distrófico e Latossolo Vermelho- 
Amarelo distrófico). Sobre as áreas de chapada desenvolvem-se campos limpos e sujos, que correspondem aproximadamente a 78\% da área do Parque (AMORIM \& BATALHA, 2007; RAMOS NETO, 2000).

Entretanto, nos vales do rio Jacuba e seus afluentes situados na porção norte e nordeste ocorre um relevo ondulado com maior incisão vertical dos canais de drenagem que propicia o desenvolvimento de um cerrado denso, mas que não excede $15 \%$ do PNE (RAMOS NETO, 2000). Ramos Neto (2000) realizou um mapeamento dos tipos vegetacionais no interior do parque, identificando também campos úmidos, veredas de buritis, campos de murundus e floresta estacional (Figura 3).

Dessa forma, a vegetação no PNE é composta basicamente pelas seguintes fitofisionomias, típicas do Cerrado:

Campo Limpo: O Campo Limpo apresenta estratos predominantemente herbáceos, com raras ocorrências de estratos arbustivos e nenhum arbóreo. Considerando o ambiente em que se encontra, é possível ser classificado nos seguintes subtipos: Campo Limpo Úmido (quando o lençol freático se encontra alto); Campo Limpo Seco (quando o lençol freático se encontra profundo); e Campo Limpo com Murundus (quando há ocorrência desses microrrelevos com elevações de 0,2 a 0,5 metros de altura e aproximadamente 1 metro de raio).

Quando há ocorrência dos Campos Limpos em áreas próximas aos cursos d'água, em áreas planas e que sofrem inundações, pode receber as denominações de Campo de Várzea, Várzea ou Brejo.

Campo Sujo: O Campo Sujo apresenta somente estratos arbustivos e herbáceos. Os arbustos e subarbustos são dispersos entre si, e são normalmente formados por indivíduos das espécies arbóreas do Cerrado Sentido Restrito que ainda não se desenvolveram por completo.

Assim como no Campo Limpo, dependendo do ambiente em que se encontra, é possível classificá-lo em três subtipos: Campo Sujo Úmido; Campo Sujo Seco; e Campo Úmido com Murundus.

Campo Cerrado: O Campo Cerrado apresenta principalmente espécies dos tipos herbáceos - subarbustivas mas também apresenta, de forma considerável, espécies arbustivas e arbóreas. Normalmente ocorre em áreas mais íngremes, onde o lençol freático é menos profundo. 


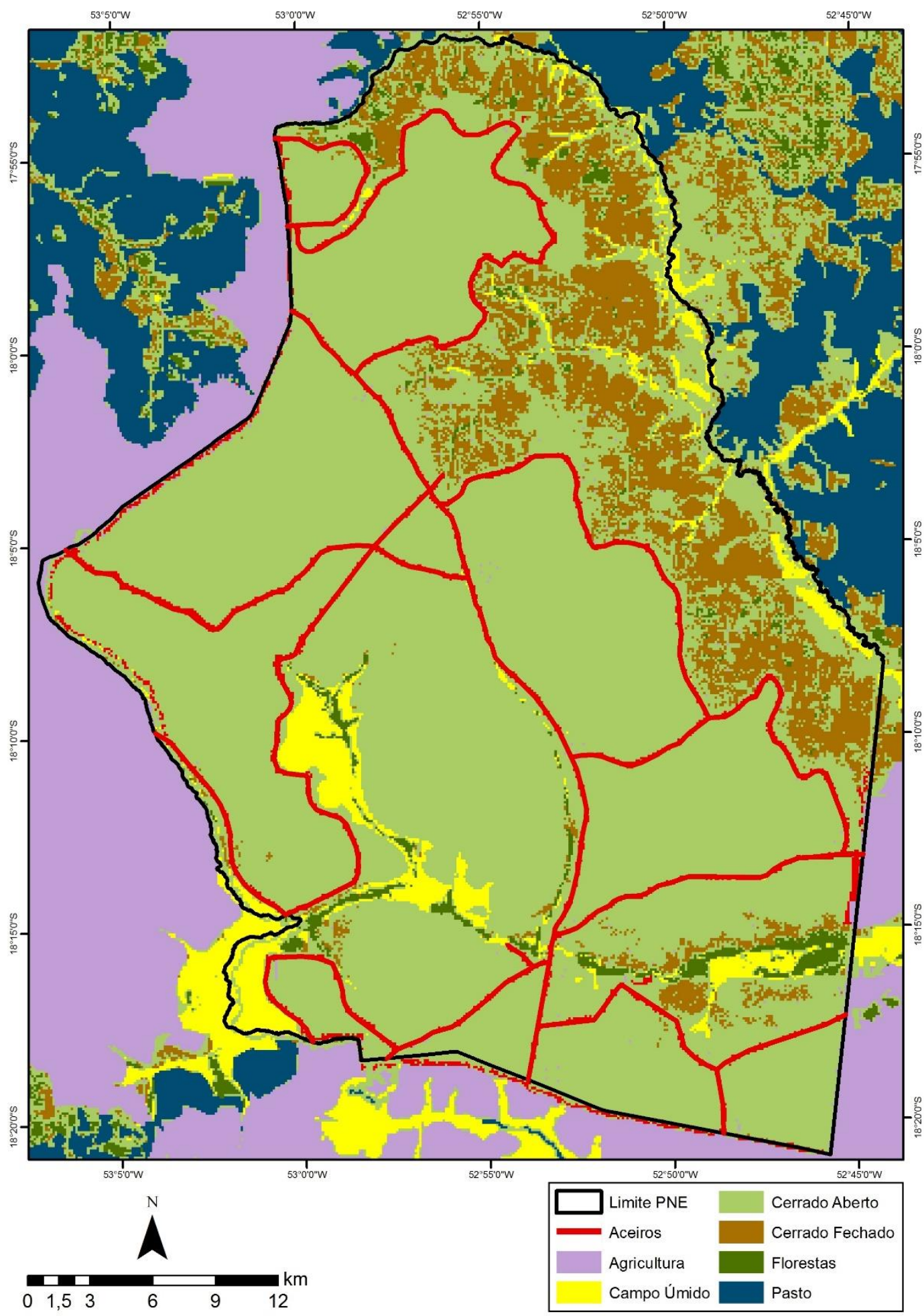

Figura 3. Mapa de vegetação e aceiros no Parque Nacional das Emas. Fonte: adaptado de Ramos Neto (2000).

Cerrado Sentido Restrito: Essa fitofisionomia apresenta estratos arbóreo e arbustivo-herbáceo, sendo que as árvores são distribuídas aleatoriamente sem que se forme um dossel contínuo. Na época das chuvas há um crescimento acelerado dos estratos 
arbustivos e herbáceos, que ficam exuberantes. Como tais estratos são mais inflamáveis, costuma-se observar evidências de queimadas nessa fitofisionomia.

Floresta Estacional Semidecídua: essa formação costuma ocorrer em locais com solos mais férteis onde inclusive a queda de folhas característica contribui para o aumento da matéria orgânica do solo. Ocorrem em áreas de interflúvio, sem associação com cursos d'água, e os níveis de caducifolia variam de acordo com as características químicas e físicas do solo. $\mathrm{O}$ dossel costuma ficar em torno de 20 metros de altura.

Floresta Ripícola: Essa fitofisionomia ocorre geralmente associada aos cursos d'água. Com isso, dependendo da distribuição das árvores e dinâmica dos dosséis, pode ser classificada da seguinte forma: Mata de Galeria, quando as copas das árvores das duas margens se tocam; Mata Ciliar, quando as copas das árvores das duas margens não se encostam; ou Mata Paludícola, quando as árvores se encontram em ambiente constantemente encharcado.

Vereda de Buritis: essa fitofisionomia apresenta a palmeira arbórea denominada Buriti (Mauritia Flexuosa) e é encontrada em locais constantemente encharcados, com solos hidromórficos. As veredas são geralmente circundadas por formações campestres úmidas, formando um bosque sempre verde, e a distribuição dos buritis não permite a formação de dosséis, como ocorre em áreas denominadas Buritizais.

Importantes estudos sobre as áreas queimadas no PNE foram realizados usando dados de sensoriamento remoto (SHIMABUKURO et al., 1991; FRANÇA \& SETZER, 1997; FRANÇA et al., 2007). FRANÇA et al. (2007) realizaram um mapeamento anual das queimadas no PNE a partir da interpretação visual de imagens dos satélites LANDSAT, considerando um período de trinta anos entre 1973 e 2003. Neste trabalho, as cicatrizes de fogo foram identificadas visualmente e consideram os seguintes estágios: (1) logo após a queimada, caracterizada por uma camada de carvão e cinza sobre o solo (alta absorção da radiação solar); (2) presença de solo exposto após a remoção da camada de carvão pela ação da chuva e vento; e (3) rebrota da vegetação que apresenta um comportamento distinto com uma intensa coloração verde sem a presença de folhas secas, que podem ser identificada visualmente em um período de até três anos.

A criação do parque em 1961 não impediu a sua utilização como pastagem pelos criadores de gado que utilizavam o fogo como estímulo para rebrota. Em 1984, o gado foi retirado eliminando definitivamente a queima intencional de pastagens no interior do Parque. No período de 1984-1994, grandes incêndios ocorreram em intervalos de três 
anos provenientes de ações antrópicas externas ao parque, com alta porcentagem de área queimada: 1985 (80\%), 1988 (74\%), 1991 (76\%), 1994 (aprox. 100\%) (FRANÇA \& SETZER, 1999, FRANÇA et al., 2007). Nos interstícios dos grandes incêndios, poucas e pequenas queimadas ocorreram. Após o grande incêndio de 1994, medidas foram adotadas para evitar incêndios antrópicos tais como: manutenção anual dos aceiros, permanência de uma brigada de bombeiros no interior da reserva durante o período de seca, e reformulação do plano de manejo (RAMOS NETO, 2000; ROCHA, 2003). Desta forma, no período 1994-2003 praticamente deixaram de ocorrer a entrada do fogo pelas propriedades vizinhas e a área queimada anual estabilizou entre 10 e $30 \%$ da área do PNE, resultantes de acidentes durante a queima dos aceiros ou queimadas naturais (durante o período chuvoso com ocorrência de raios) (FRANÇA et al., 2007). Trabalhos realizados durante o período entre 2002-2003 (FRANÇA et al., 2004) e 2003-2004 (PEREIRA \& FRANÇA, 2005) confirmam que a grande maioria dos eventos de fogo tornaram a ser proveniente de causas naturais desencadeados por raios. O novo padrão de queimadas caracteriza-se por áreas de tamanhos menores, datas e localizações variadas, que gera um verdadeiro mosaico na cobertura vegetal do PNE. 


\section{MATERIAIS E MÉTODOS}

\subsection{Imagens MODIS}

O sensor MODIS (Moderate Resolution Imaging Spectroradiometer) é um dos instrumentos componentes dos satélites TERRA e AQUA, lançados nos anos de 1999 e 2002, respectivamente. Os dados deste sensor colaboram nos estudos de avaliação das mudanças globais, já que possui ampla cobertura espacial (BARKER et al., 1992), alta resolução temporal (JUSTICE et al., 2002) e contém 36 bandas adequadas para a observação das propriedades da vegetação e cobertura terrestre, da temperatura dos oceanos e das propriedades das nuvens (SALOMONSON \& TOLL, 1991). As imagens MODIS estão disponíveis gratuitamente no site da agência NASA (National Aeronautics and Space Administration), contendo georreferenciamento e correção dos efeitos atmosféricos, tais como nuvens, aerossóis, entre outros (WOLF et al., 2002). O sensor MODIS tem sido amplamente utilizado para o monitoramento de áreas queimadas em escala regional e global (ROY et al., 2005; GIGLIO et al., 2006; BOSCHETTI et al., 2008 a,b; CHUVIECO et al., 2005).

O presente trabalho utilizou uma série temporal do período 2001-2014 referente aos produtos de reflectância de superfície (MOD09A1 e MOD09Q1), considerando as bandas 2 (infravermelho próximo- NIR) do produto MOD09Q1 e a banda 7 (infravermelho de ondas curtas - SWIR) do produto MOD09A1. Tais produtos apresentam resoluções espaciais de 250m (MOD09Q1) e 500m (MOD09A1), entretanto as imagens MOD09A1 foram reamostradas para $250 \mathrm{~m}$. As imagens são composições de oito dias com o propósito de eliminar ou reduzir a quantidade de nuvens e ruídos nas imagens. As imagens originais foram obtidas em formato HDF (Hierarchical Data Format) e convertidas para o formato Geotiff por meio do programa MRT (MODIS Reprojection Tool) disponibilizado no site da NASA.

Após a conversão, as imagens MODIS foram estruturadas em um cubo temporal onde as imagens apresentam uma sequência crescente ao longo do tempo utilizando o programa ENVI 4.7. Dessa forma, os eixos " $x$ " e " $y$ " do cubo representam as coordenadas geográficas, o eixo "z” representa o tempo (CARVALHO JÚNIOR et al., 2009) (Figura 4). Assim, as mudanças de cada pixel ao longo do tempo podem ser representadas em um perfil temporal. O cubo temporal do PNE é constituído por 644 imagens, contendo 46 imagens por anos relativos a composição de oito dias. 


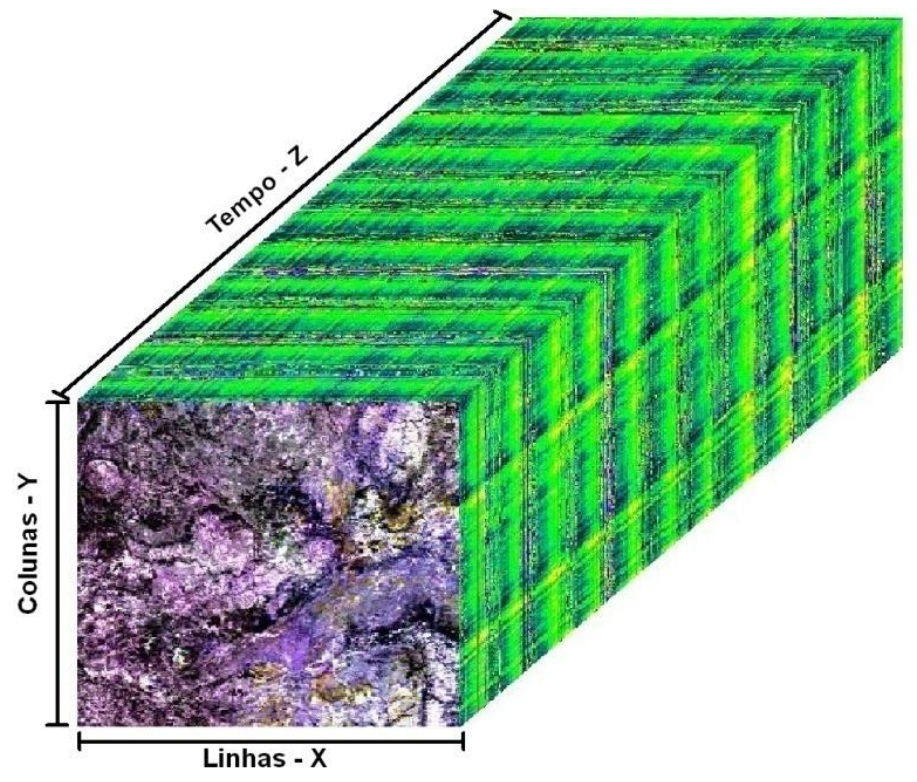

Figura 4. Representação do cubo 3D temporal de imagens do sensor MODIS.

\section{2. Índices Espectrais}

Os índices espectrais são formulações algébricas entre bandas que possibilitam realçar determinados alvos em análise. Com essas operações é possível diminuir a variabilidade ocasionada por fatores externos, por exemplo, sombras ou espalhamento atmosférico, e maximizar a resposta dos alvos pretendidos (SAMPAIO, 2007). Na presente pesquisa, foi aplicado o índice NBR para as séries temporais MODIS. O índice NBR é o mais comumente usado para detecção de áreas queimadas, expresso pela relação entre as bandas do Infravermelho Próximo (NIR) e do Infravermelho Médio (SWIR).

$$
N B R=\frac{(N I R-S W I R)}{(N I R+S W I R)}
$$

Os valores de NBR variam entre -1 e +1 , onde os valores mais próximos de -1 correspondem às áreas queimadas. $\mathrm{O}$ índice NBR é um dos mais utilizados para a avaliação de severidade das queimadas (VERAVERBEKE et al, 2012; MILLER \& THODE, 2007). O consumo da vegetação pelo fogo ocasiona uma diminuição dos valores de NIR em relação ao SWIR. O SWIR é comumente absorvido pela água, indicando o conteúdo de água tanto em solos como vegetação (MILLER \& THODE, 2007). Portanto, por conta da retirada de água da vegetação durante a queimada, áreas afetadas pelo fogo aumentam sua reflectância nesse comprimento de onda, o que também facilita o contraste em relação a áreas não queimadas. Com isso, a formulação do NBR busca a maximização 
das variações de reflectância ocorridas durante os eventos de queimadas, dando maior contraste e separabilidade dessas áreas (LOZANO et al., 2007).

\subsection{Tratamento de Ruídos}

Os dados de séries temporais comumente possuem grande quantidade de nuvens e ruídos decorrentes de interferências atmosféricas ou fatores do próprio sensor, como oscilação. Tais interferências podem ser identificadas por sua discrepância em relação aos dados circunvizinhos tanto espacialmente como ao longo do tempo. Portanto, para garantir um mapeamento mais preciso, evitando classificações errôneas, é necessário minimizar ou até mesmo eliminar os ruídos por meio da aplicação de filtros ou transformações de dados.

No presente trabalho foi utilizado o filtro Savitzky-Golay (S-G) (SAVITZKY \& GOLAY, 1964). O S-G consiste basicamente em uma janela móvel de convolução com um filtro ponderado, onde o peso é dado por um polinômio de um determinado grau definido pelo usuário (CHEN, 2004). As principais características deste filtro são: capacidade de preservar os valores extremos (máximos e mínimos) da amostra analisada (ZHAO et al., 2009), habilidade de ser utilizado em qualquer sequência de dados com intervalos fixos e uniformes (CHEN, 2004) e não necessita transformar o sinal para o domínio da frequência (STAVROULAKIS et al., 2013).

No estudo de áreas queimadas, a característica do filtro S-G de preservar os valores de mínima é uma importante vantagem em comparação a outros métodos, uma vez que após o evento de fogo, observa-se uma queda abrupta dos índices espectrais (VERBESSELT, 2006). A escolha do filtro é uma importante etapa, pois as áreas queimadas devido a sua acentuada variação podem ser confundidas com ruído. O S-G, concebido para ser utilizado em dados de análise química, permite distinguir os picos provenientes de sinais com relação aos ruídos. Portanto, o filtro $\mathrm{S}-\mathrm{G}$ tem sido amplamente utilizado em séries temporais com o propósito de mapeamento de áreas queimadas (VERAVERBEKE et al., 2010, CARVALHO JÚNIOR et al.,2015, KINOSHITA \& HOGUE, 2011).

Normalmente, as técnicas de filtragem podem ser subdivididas em dos tipos de métodos conforme o seu propósito: eliminação dos ruídos de impulso ou suavização da série temporal. No presente trabalho, o método Savitzky-Golay foi utilizado com ambas 
as finalidades (DE CARVALHO JÚNIOR, 2015). Na detecção e eliminação do ruído de impulso, realizou-se uma subtração entre a curva filtrada pelo método S-G e os dados originais. Os pontos ruidosos são individualizados quando o valor absoluto da subtração exceder um limite definido pelo usuário. Os pontos demarcados com ruídos de impulso são substituídos por dados interpolados linearmente a partir dos pontos anteriores e posteriores ao ruído. Após a eliminação dos picos ruidosos foi realizada uma filtragem SG convencional para suavizar a série temporal. No presente trabalho, ambos os procedimentos foram realizados no programa ABÍLIO desenvolvido em linguagem $\mathrm{C}++$ (CARVALHO JÚNIOR et al., 2008). Diferentes testes foram realizados para determinar os parâmetros do método S-G (dimensão da janela e grau de polinômio) mais adequados para a pesquisa.

\subsection{Normalização pela Média das assinaturas temporais e a detecção das áreas queimadas}

A detecção de áreas queimadas é determinada por um valor limite do índice espectral, que a partir dele estabelece a sua presença ou ausência. No entanto, os valores limites variam conforme o bioma ou mesmo a partir de fitofisionomias (LOBODA et al., 2007). As diversas fitofisionomias do Cerrado apresentam diferenciação de acordo com o grau de ocorrência de espécies lenhosas, arbustivas ou gramíneas, que resultam em comportamentos distintos das séries temporais de índices de vegetação. Embora a ocorrência de queimadas cause uma diminuição abrupta nos valores dos índices NBR e NDVI nos diferentes tipos de vegetação, o valor absoluto não é igual. Este comportamento distinto entre as fisionomias dificulta a definição de um único valor limite dos índices espectrais na individualização das áreas queimadas, tornando o processo mais complexo e vulnerável a erros.

No presente trabalho, são utilizadas as séries temporais normalizadas pela Média (nmNBR), que permite a comparação entre as séries temporais provenientes de ambientes distintos. Além disso, o método de normalização em comparação a diferença interanual não altera a relação sinal/ruído e não gera feições que possam ser confundidos com as áreas queimadas. A normalização pela Média (m) utiliza a seguinte formulação:

$$
m=x-\mu
$$


Onde "x" é a própria série temporal e " $\mu$ " se refere à média da série temporal. As séries normalizadas possibilitam a definição de um limiar único para o corte das áreas queimadas considerando os valores de desvio padrão.

Normalmente, a detecção do valor limite é feito de forma empírica, dependendo do conhecimento do analista (LOBODA et al, 2007). Neste trabalho, foi utilizado um método automatizado proposto por de Carvalho Júnior et al. (2015), que define um valor limite ótimo a partir da comparação entre o mapa de verdade das áreas queimadas, previamente feito a partir de imagens com melhor resolução espacial, e a imagem do índice espectral MODIS. O algoritmo realiza testes para uma série contínua de valores limites e determina o melhor resultado a partir do maior valor atingido para os coeficientes de acurácia Kappa e Overall. Estes coeficientes são amplamente utilizados na análise da acurácia de classificações de imagens de sensoriamento remoto (CONGALTON \& GREEN, 1999). O coeficiente Overall corresponde à divisão da soma dos pixels classificados de forma correta pelo total de pixels da classe. Dessa forma, os valores variam de 0 a 100\%. Já o índice Kappa, segundo Landis \& Koch (1977), pode ser interpretado a partir do seguinte quadro de valores:

\begin{tabular}{|c|c|}
\hline Valores Kappa & Classificação \\
\hline$<0.00$ & Inferior \\
\hline $\mathbf{0 . 0 0}-\mathbf{0 . 2 0}$ & Fraco \\
\hline $\mathbf{0 . 2 1}-\mathbf{0 . 4 0}$ & Razoável \\
\hline $\mathbf{0 . 4 1}-\mathbf{0 . 6 0}$ & Moderado \\
\hline $\mathbf{0 . 6 1}-\mathbf{0 . 8 0}$ & Forte \\
\hline $\mathbf{0 . 8 1}-\mathbf{1 . 0 0}$ & Quase perfeito \\
\hline
\end{tabular}

Para a área de estudo, foi tomada a interpretação visual de imagens dos satélites LANDSAT e Resourcesat como a referência utilizada para a verificação da acurácia do mapeamento elaborado com os dados MODIS.

3.5. Análise comparativa com sensores de mais alta resolução espacial (TMLANDSAT-5, LANDSAT-8/OLI e Resourcesat-1)

Para a validação dos mapeamentos de queimadas realizados a partir das imagens MODIS foram utilizadas imagens com melhor resolução espacial: TM-LANDSAT-5, LANDSAT-8/OLI e Resourcesat-1. Os sensores de média e alta resolução espacial 
permitem um delineamento mais preciso dos eventos de queimadas, principalmente as pequenas e mais fragmentadas ocorrências (LARIS, 2005).

O Thematic Mapper (TM) é um sensor multiespectral a bordo dos satélites LANDSAT 4 e 5, que gera imagens em 7 bandas espectrais. As bandas 1, 2, 3, 4, 5 e 7 geram imagens nas faixas do visível, infravermelho próximo e médio, e têm resolução espacial de 30 metros. A banda 6 é a do infravermelho termal e tem resolução espacial de 120 metros. Esses satélites tem resolução temporal de 16 dias e, portanto, recobre o mesmo ponto na superfície terrestre entre uma a duas vezes ao mês. Por conta disso, é bastante utilizado nas áreas de monitoramentos terrestres, além de suas aplicações nos ramos de mineralogia e estudos da dinâmica urbana.

Desde 2013, o satélite LANDSAT 8 tem feito o imageamento da terra com seus sensores Operational Land Imager (OLI) e Thermal Infrared Sensor (TIRS). O sensor OLI gera 9 bandas espectrais, sendo as bandas 1, 2, 3 e 4 nas faixas do visível, as 5, 6 e 7 nas faixas do infravermelho próximo e médio, e a banda 9 voltada para detecção de nuvens cirrus, todas com 30m de resolução espacial e a 8 como banda pancromática e $15 \mathrm{~m}$ de resolução espacial. O sensor TIRS gera duas bandas na faixa do termal, com $100 \mathrm{~m}$ de resolução espacial. As imagens TM e OLI são disponibilizadas gratuitamente, com georreferenciamento, no site do Serviço Geológico dos Estados Unidos (USGS), sendo que as imagens TM tem recobrimento somente até o ano de 2011. A área de estudo é coberta por duas cenas LANDSAT (órbitas-ponto 224/72 e 224/73), que foram unidas em um mosaico e classificadas.

Em 2003, houve o lançado o satélite indiano Resourcesat-1, que tinha a bordo os sensores LISS-3 (Linear Imaging Self Scanner), LISS-4, AWiFS-A (Advanced Wide Field Sensor) e AWiFS-B. O sensor LISS-3 gera imagens em quatro bandas espectrais, sendo duas bandas na faixa do visível (Verde e Vermelho) e duas na faixa do infravermelho (Próximo e Médio). O satélite possui um intervalo de revisita de 24 dias e fornece imagens com 23,5 metros de resolução espacial. As imagens Resourcesat- 1 foram também utilizadas para referência dos mapeamentos de queimadas somente no ano de 2012, visto que não há cobertura de imagens LANDSAT nesse ano. Foram adquiridas no site do Instituto Nacional de Pesquisas Espaciais (INPE), e passaram pelos procedimentos de correção radiométrica, geométrica e classificação. Não houve necessidade da 
montagem de um mosaico, já que a área de interesse é totalmente coberta pelas imagens da órbita-ponto 324/90 deste satélite.

A Tabela 1 lista o conjunto de imagens utilizadas no mapeamento das áreas queimadas referentes ao intervalo de 2001 a 2014. Todas as imagens citadas apresentavam ocorrências de queimadas dentro da área do PNE, entretanto, todas a imagens disponíveis no período de estudo foram consultadas com o objetivo de identificar quais apresentavam áreas queimadas. A maioria dos mapeamentos dos eventos de fogo foi feito por interpretação visual e vetorização das cicatrizes por meio do programa ArcGIS 10.1. Especificamente, nos anos 2005 e 2010 com maiores ocorrências de área queimada, utilizou-se a classificação supervisionada por Máxima Verossimilhança no ENVI 4.7, com posterior edição manual do resultado no ArcGIS 10.1.

Tabela 1. Imagens utilizadas para o mapeamento das cicatrizes de fogo ao longo o período 2001-2014.

\begin{tabular}{|c|c|c|c|c|c|c|c|}
\hline Ano & Satélite & Sensor & \multicolumn{5}{|c|}{ Datas } \\
\hline \multirow{2}{*}{2001} & \multirow{2}{*}{ LANDSAT 5} & \multirow{2}{*}{$\mathrm{TM}$} & $22 / 01 / 2001$ & 07/02/2001 & $17 / 07 / 2001$ & 02/08/20011 & 8/08/20011 \\
\hline & & & \begin{tabular}{|l|}
$09 / 09 / 2001$ \\
\end{tabular} & \begin{tabular}{|l|}
$06 / 11 / 2001$ \\
\end{tabular} & $08 / 12 / 2001$ & & \\
\hline 2002 & LANDSAT 5 & $\mathrm{TM}$ & $25 / 01 / 2002$ & $14 / 03 / 2002$ & $30 / 03 / 2002$ & $15 / 04 / 2002$ & $04 / 07 / 2002$ \\
\hline 2003 & LANDSAT 5 & $\mathrm{TM}$ & $23 / 07 / 2003$ & $24 / 08 / 2003$ & $25 / 09 / 2003$ & $14 / 12 / 2003$ & $30 / 12 / 2003$ \\
\hline \multirow{2}{*}{2004} & \multirow{2}{*}{ LANDSAT 5} & \multirow{2}{*}{$\mathrm{TM}$} & $20 / 04 / 2004$ & $22 / 05 / 2004$ & $07 / 06 / 2004$ & $10 / 08 / 2004$ & $26 / 08 / 2004$ \\
\hline & & & $11 / 09 / 2004$ & $27 / 09 / 2004$ & $29 / 10 / 2004$ & $14 / 11 / 2004$ & $16 / 12 / 2004$ \\
\hline \multirow{2}{*}{2005} & \multirow{2}{*}{ LANDSAT 5} & \multirow{2}{*}{$\mathrm{TM}$} & 06/03/2005 & $12 / 07 / 2005$ & $13 / 08 / 2005$ & $29 / 08 / 2005$ & $30 / 09 / 2005$ \\
\hline & & & $16 / 10 / 2005$ & & & & \\
\hline \multirow{3}{*}{2006} & \multirow{3}{*}{ LANDSAT 5} & \multirow{3}{*}{$\mathrm{TM}$} & $05 / 02 / 2006$ & $21 / 02 / 2006$ & $26 / 04 / 2006$ & $12 / 05 / 2006$ & $28 / 05 / 2006$ \\
\hline & & & 13/06/2006 & $15 / 07 / 2006$ & $31 / 07 / 2006$ & $17 / 09 / 2006$ & 03/10/2006 \\
\hline & & & $19 / 10 / 2006$ & $04 / 11 / 2006$ & $20 / 11 / 2006$ & $22 / 12 / 2006$ & \\
\hline \multirow{2}{*}{2007} & \multirow{2}{*}{ LANDSAT 5} & \multirow{2}{*}{$\mathrm{TM}$} & $28 / 03 / 2007$ & $29 / 04 / 2007$ & $15 / 05 / 2007$ & $31 / 05 / 2007$ & $02 / 07 / 2007$ \\
\hline & & & $03 / 08 / 2007$ & $19 / 08 / 2007$ & $04 / 09 / 2007$ & $20 / 09 / 2007$ & \\
\hline \multirow{2}{*}{2008} & \multirow{2}{*}{ LANDSAT 5} & \multirow{2}{*}{$\mathrm{TM}$} & $30 / 03 / 2008$ & $04 / 07 / 2008$ & $20 / 07 / 2008$ & $21 / 08 / 2008$ & $06 / 09 / 2008$ \\
\hline & & & $22 / 09 / 2008$ & $08 / 10 / 2008$ & & & \\
\hline 2009 & LANDSAT 5 & $\mathrm{TM}$ & $07 / 07 / 2009$ & 08/08/2009 & $09 / 09 / 2009$ & $11 / 10 / 2009$ & \\
\hline 2010 & LANDSAT 5 & $\mathrm{TM}$ & $21 / 04 / 2010$ & 08/06/2010 & $26 / 07 / 2010$ & $27 / 08 / 2010$ & $12 / 09 / 2010$ \\
\hline \multirow{2}{*}{2011} & \multirow{2}{*}{ LANDSAT 5} & \multirow{2}{*}{$\mathrm{TM}$} & $08 / 04 / 2011$ & $24 / 04 / 2011$ & $14 / 08 / 2011$ & $30 / 08 / 2011$ & $15 / 09 / 2011$ \\
\hline & & & $02 / 11 / 2011$ & & & & \\
\hline 2012 & Resourcesat & LISS3 & $13 / 10 / 2012$ & $24 / 12 / 2012$ & & & \\
\hline \multirow{2}{*}{2013} & \multirow{2}{*}{ LANDSAT 8} & \multirow{2}{*}{ OLI } & $02 / 07 / 2013$ & $18 / 07 / 2013$ & $03 / 08 / 2013$ & $04 / 09 / 2013$ & $09 / 12 / 2013$ \\
\hline & & & $25 / 12 / 2013$ & & & & \\
\hline
\end{tabular}


Para as comparações, os mapeamentos de áreas queimadas foram aglutinadas em períodos anuais, tanto para as séries nmNBR-MODIS, como também, utilizando sensores com melhores resoluções (TM-LANDSAT-5, LANDSAT-8/OLI e Resourcesat-1) (Figura 5). Entretanto foram mantidas as datas das queimadas para avaliação do período de ocorrência (período seco ou chuvoso) e tamanho dos polígonos. Os mapas anuais de áreas queimadas a partir dos dois tipos de dados foram comparados pelos índices Kappa e Overall. Desta forma, uma comparação dos mapeamentos das queimadas ao longo dos 14 anos estudados foi realizada, evidenciando as diferenças e as possíveis complementaridades entre os dados.

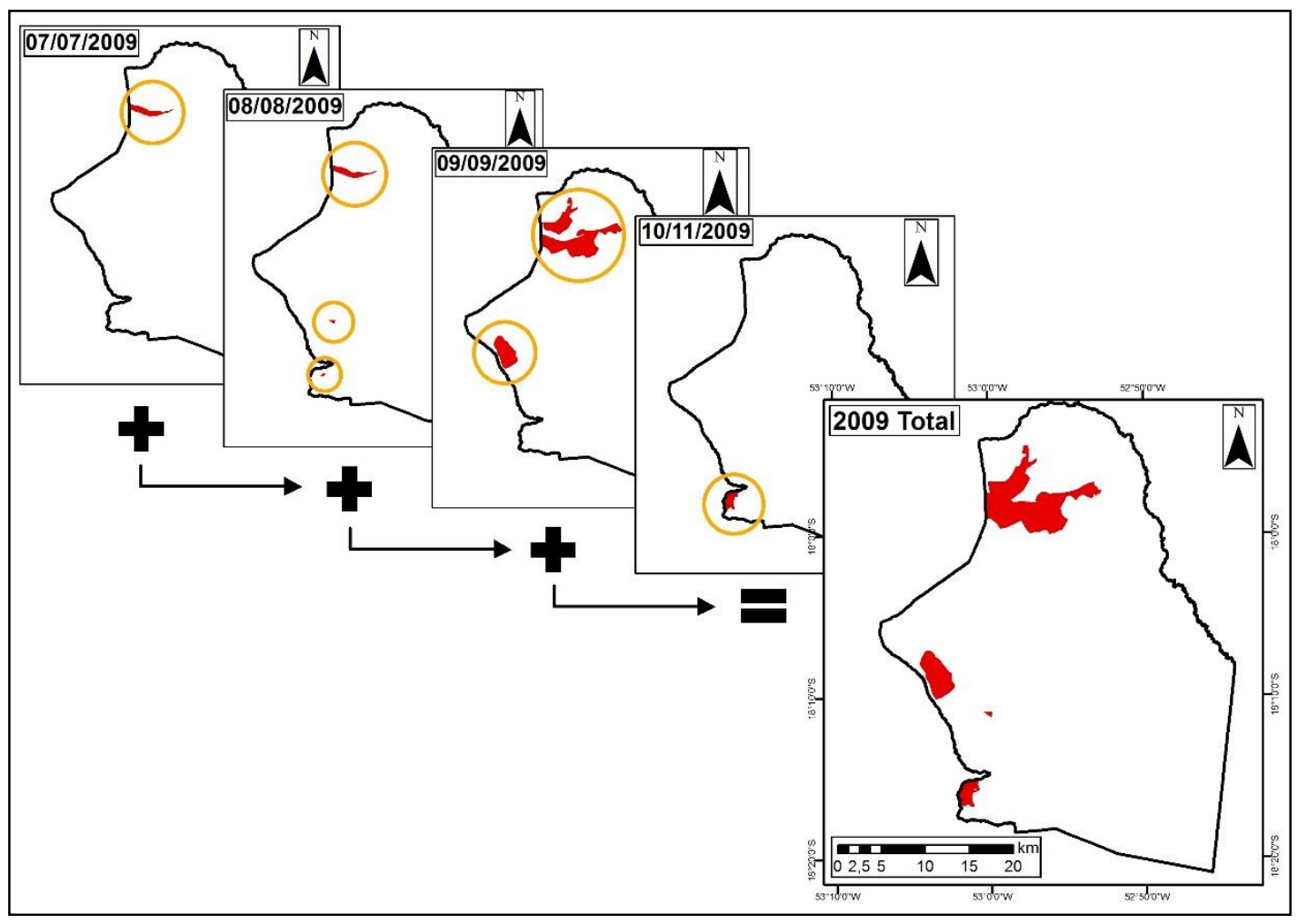

Figura 5. Somatório para agrupamento das cicatrizes de queimadas por ano. 


\section{RESULTADOS}

\subsection{Resultado do Tratamento de Ruídos}

No presente trabalho o filtro $S-G$ foi utilizado tanto para a eliminação dos ruídos de impulso como para a suavização da série temporal. Com o propósito de eliminar os ruídos de impulso foi utilizada uma filtragem S-G com um polinômio de 5 ordem que foi subtraído do dado original. Os valores absolutos da subtração maiores que 0,09 NBR foram considerados como ruído e substituídos pelos valores da interpolação linear, em contraposição nos casos de valores inferiores foram mantidos os dados originais. Por fim, uma nova filtragem S-G foi aplicada para a suavização da série temporal considerando uma janela de mesmo tamanho e polinômio de mesma ordem. Os coeficientes testados foram sempre pequenos, por causa das áreas com predomínio da vegetação herbácea que apresentavam uma rápida recuperação após os eventos de fogo, contendo um pico negativo no índice NBR de curta duração. Portando, na série temporal NBR-MODIS com composições de oito dias não foi possível utilizar coeficientes maiores para evitar a perda destes eventos de queimadas. A Figura 6 demonstra o tratamento do perfil espectral utilizando diferentes coeficientes. Com isso, observou-se que quanto maior a ordem do polinômio, maior a quantidade de informação considerada como ruído e eliminada. Observa-se que a utilização do polinômio de 9 ordem descreve uma curva com formato e valores de picos divergentes do dado original. A Figura 7 demonstra as diferentes etapas de filtragem S-G das séries temporais. A definição dos parâmetros utilizados na filtragem S-G foi realizada minuciosamente de forma a provocar uma suavização dos ruídos, mas mantendo as feições de queimadas. 


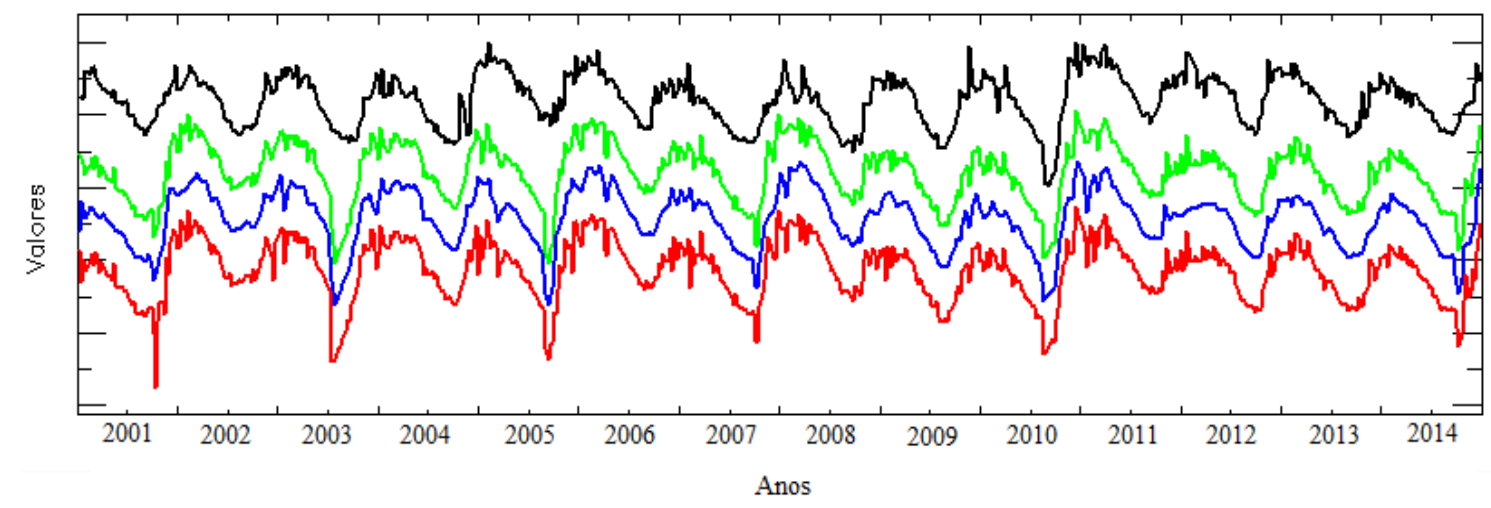

Figura 6. Comparação entre a série temporal NBR original (curva vermelha), a filtragem Savitzky-Golay com polinômio 5 (curva azul), S-G com polinômio 7 (curva verde) e SG com polinômio 9 (curva preta).

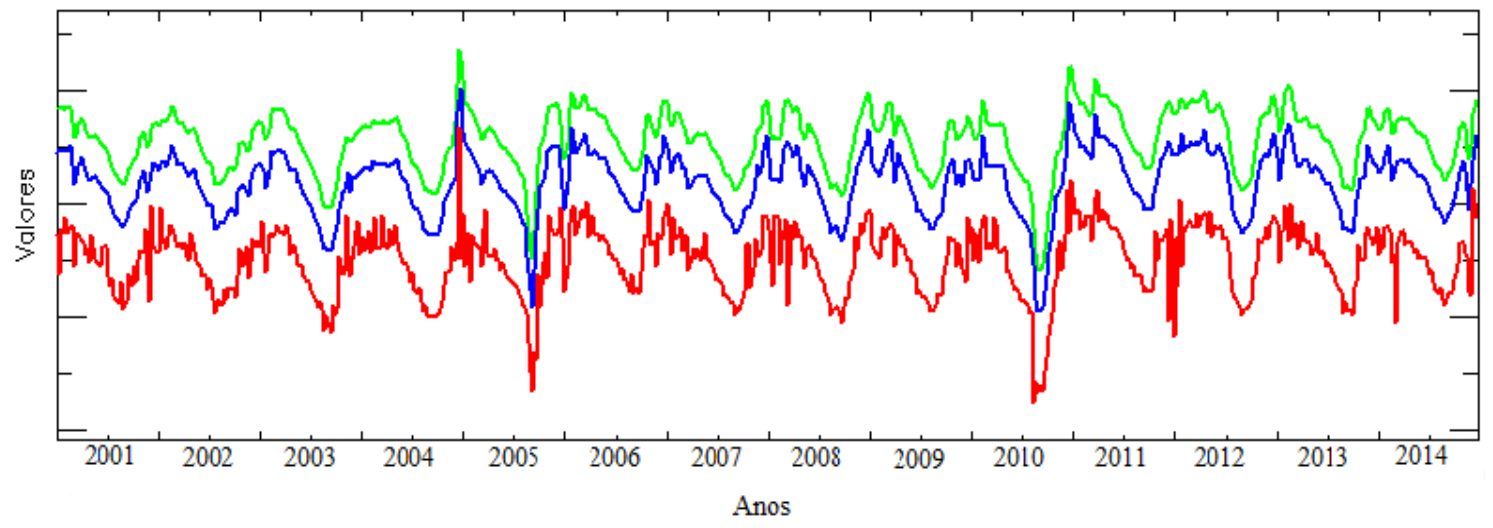

Figura 7. Comparação entre a série temporal NBR original (curva vermelha), a filtragem Savitzky-Golay com polinômio 5 e limite igual a 0,09 para eliminação dos ruídos de impulso (curva azul), e S-G com mesmo polinômio e sem limite de corte para a suavização (curva verde).

\subsection{Detecção das Áreas Queimadas a partir das Séries Temporais Normalizadas pela Média}

A Figura 8 compara a imagem NBR original e a nmNBR, evidenciando que as imagens normalizadas apresentam um significativo realce visual das áreas queimadas em comparação a imagem original. Percebe-se a padronização dos valores circunvizinhos à área queimada, dando maior destaque para a queimada. Além disso, a normalização permitiu homogeneizar as séries temporais de diferentes fitofisionomias do Cerrado e suas respectivas respostas ao fogo. A Figura 9 demonstra duas séries temporais NBR de dois ambientes distintos dentro do PNE e as suas respectivas séries nmNBRs. A sobreposição das feições de fogo tornou evidente a compatibilização dos dados e a melhor definição dos eventos de fogo. 

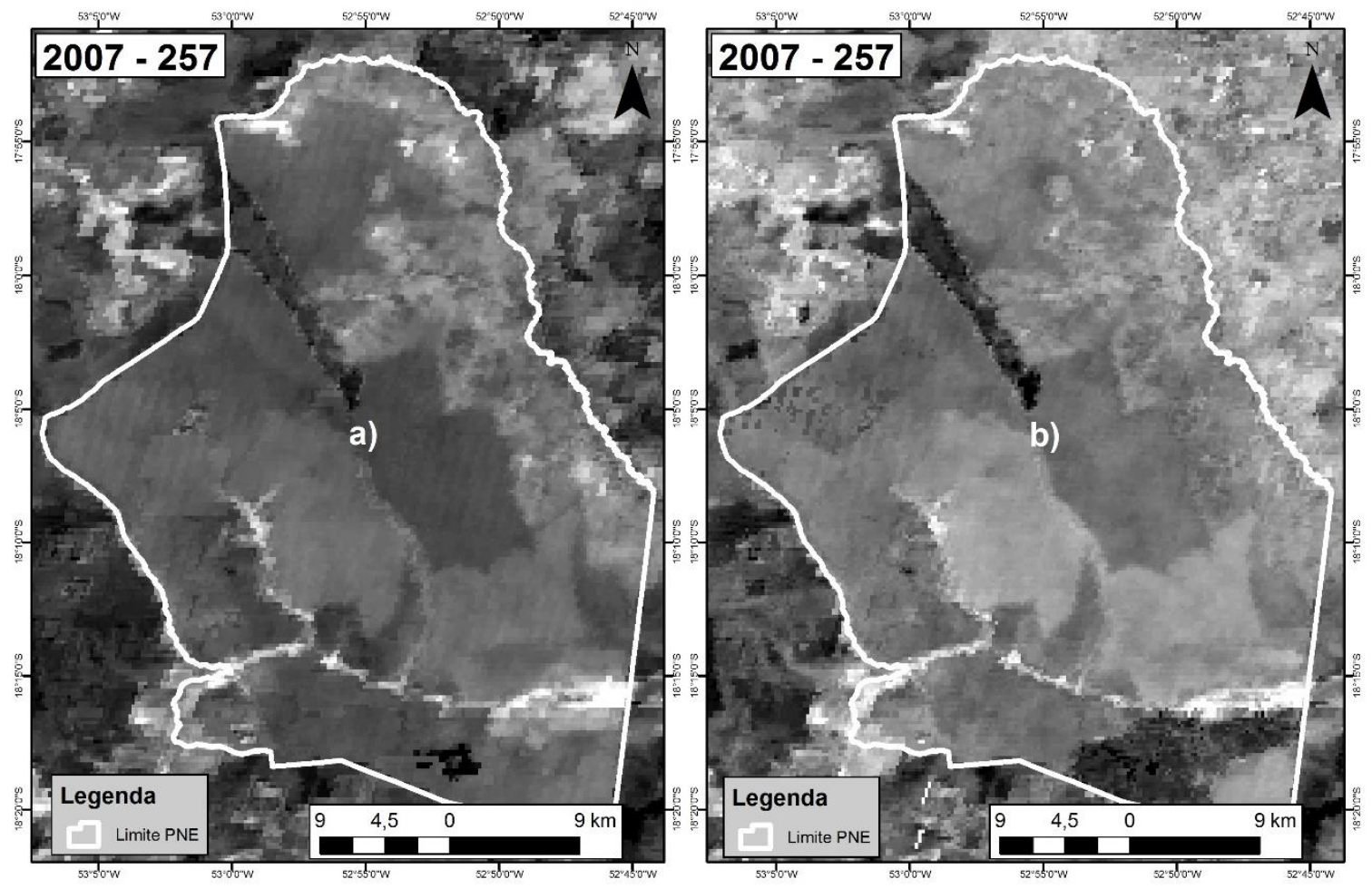

Figura 8. Comparação entra as imagens a) NBR original e b) nmNBR no ano de 2007.
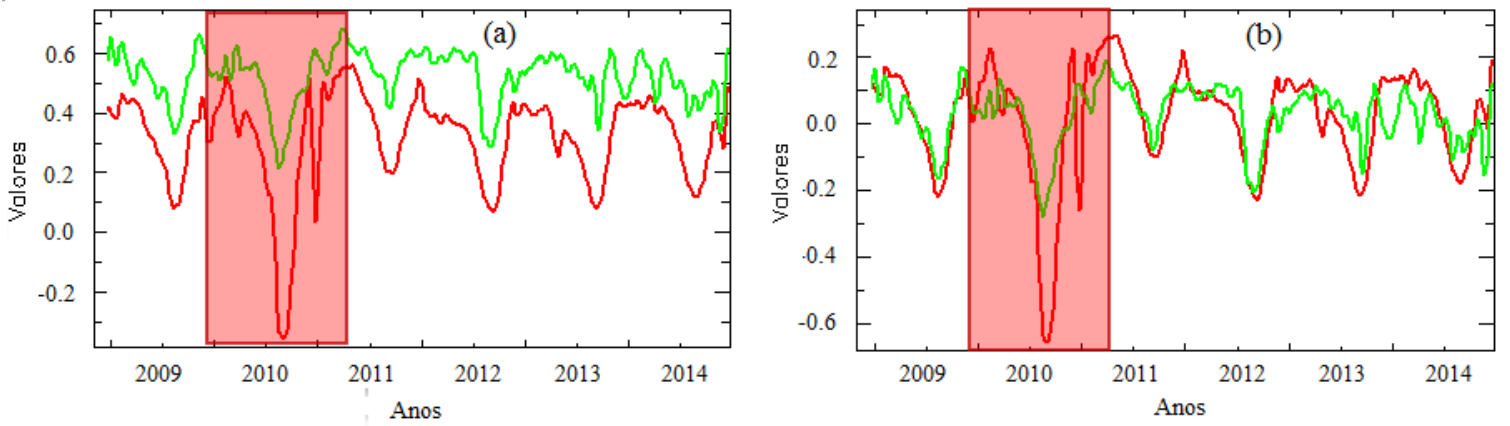

Figura 9. Comparação entre as séries temporais NBR (a) e nmNBR (b). Destaque para a normalização da feição de fogo.

A partir desta homogeneização entre as séries temporais foi investigado o valor limite ótimo para separação das ocorrências de queimadas. Os mapeamentos elaborados com as imagens LANDSAT e Resourcesat referente às datas 30/09/2005 (2005 - 273), 27/08/2010 (2010 - 239) e 09/10/2014 (2014 - 282) foram utilizados como as informações verdadeiras das áreas queimadas (Figura 10, 11 e 12). Estes mapeamentos são comparados com o índice nmNBR relativo a composição de oito dias das datas 2005/257, 2010/241 e 2014/281. O programa Abílio realizou o teste considerando uma série de 50 valores limites e retornou um gráfico com os seus respectivos coeficientes Kappa e Overall. Nos testes do melhor limiar foi utilizada uma máscara com o limite do 
parque para que os valores das áreas externas ao PNE não tivessem influência no resultado final. As Figuras 13, 14 e 15 demonstram os gráficos dos coeficientes de acurácia, evidenciando um valor limite ótimo e os respectivos valores Kappa e Overall na avaliação de cada um dos três anos. Para o ano de 2005, foi definido um valor limite ótimo de -0,361. Com a aplicação desse limiar, os coeficientes de acurácia apresentaram os valores 77,482 para o Kappa e 89,141 para o Overall. Já para o ano de 2010, o limite ótimo observado foi de -0,334. Com isso, os coeficientes de acurácia apresentaram os valores 72, 392 para o Kappa e 94,842 para Overall. Por fim, o limite ótimo observado no ano de 2014 foi de -0,258. Com a aplicação desse limiar, os coeficientes apresentaram valores de 95,519 para o Kappa e 99,295 para Overall. Os índices de acurácia demonstram valores adequados para o mapeamento das áreas queimadas, principalmente considerando a diferença de resolução espacial do sensor MODIS em relação ao LANDSAT e Resourcesat. Para a aplicação do melhor limiar em toda a série temporal, foi utilizada a média aritmética dos limiares encontrados nos anos de 2005, 2010 e 2014. Dessa forma, foi utilizado o valor $-0,318$ como limite ótimo final em toda a série temporal no período de 2001-2014, gerando uma sucessão de máscaras com os eventos de queimadas.
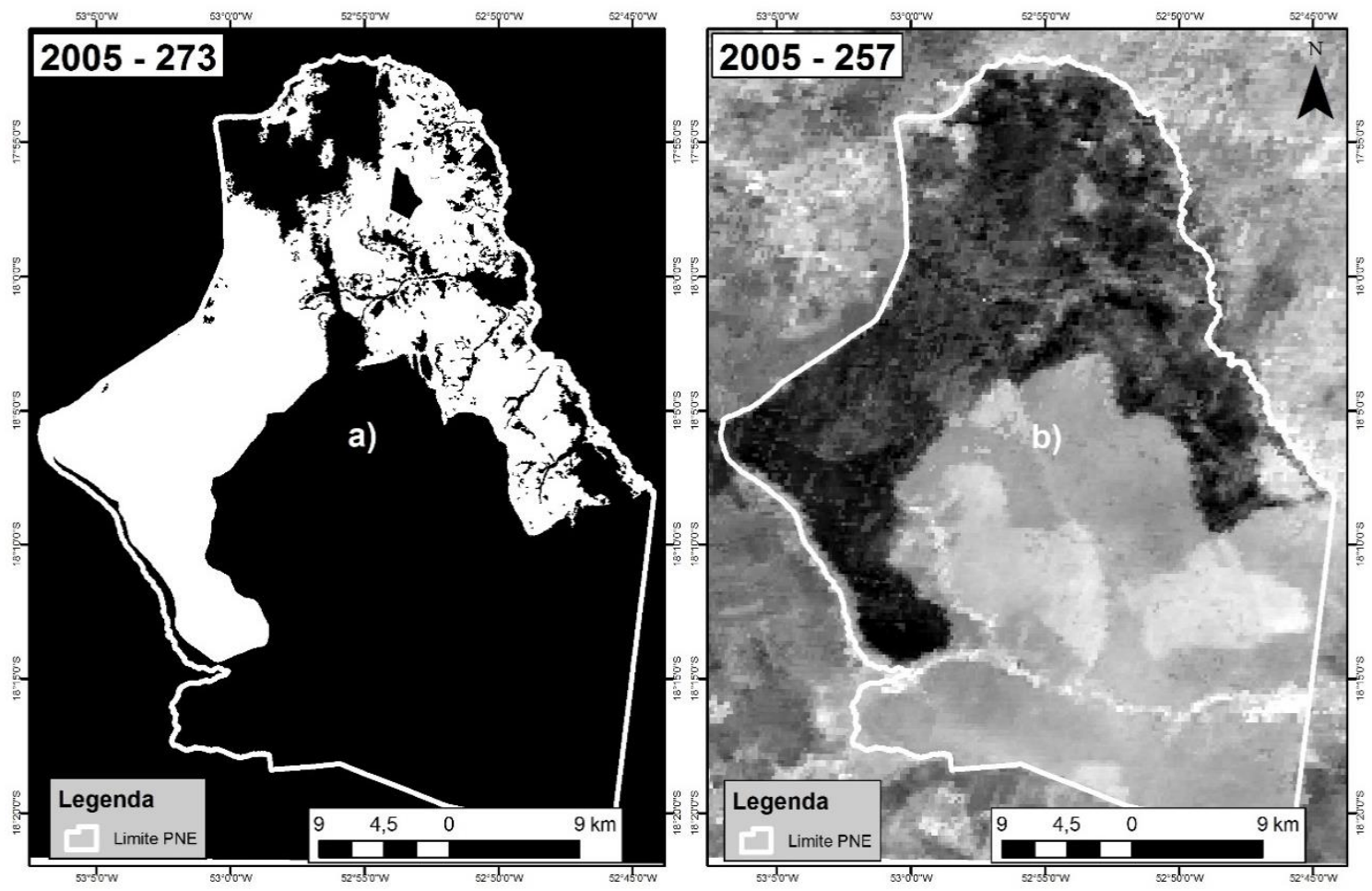

Figura 10. Classificação usada como imagem-verdade na determinação do limiar ótimo (a) e imagem normalizada (nmNBR) utilizada na comparação (b), ano 2005. 

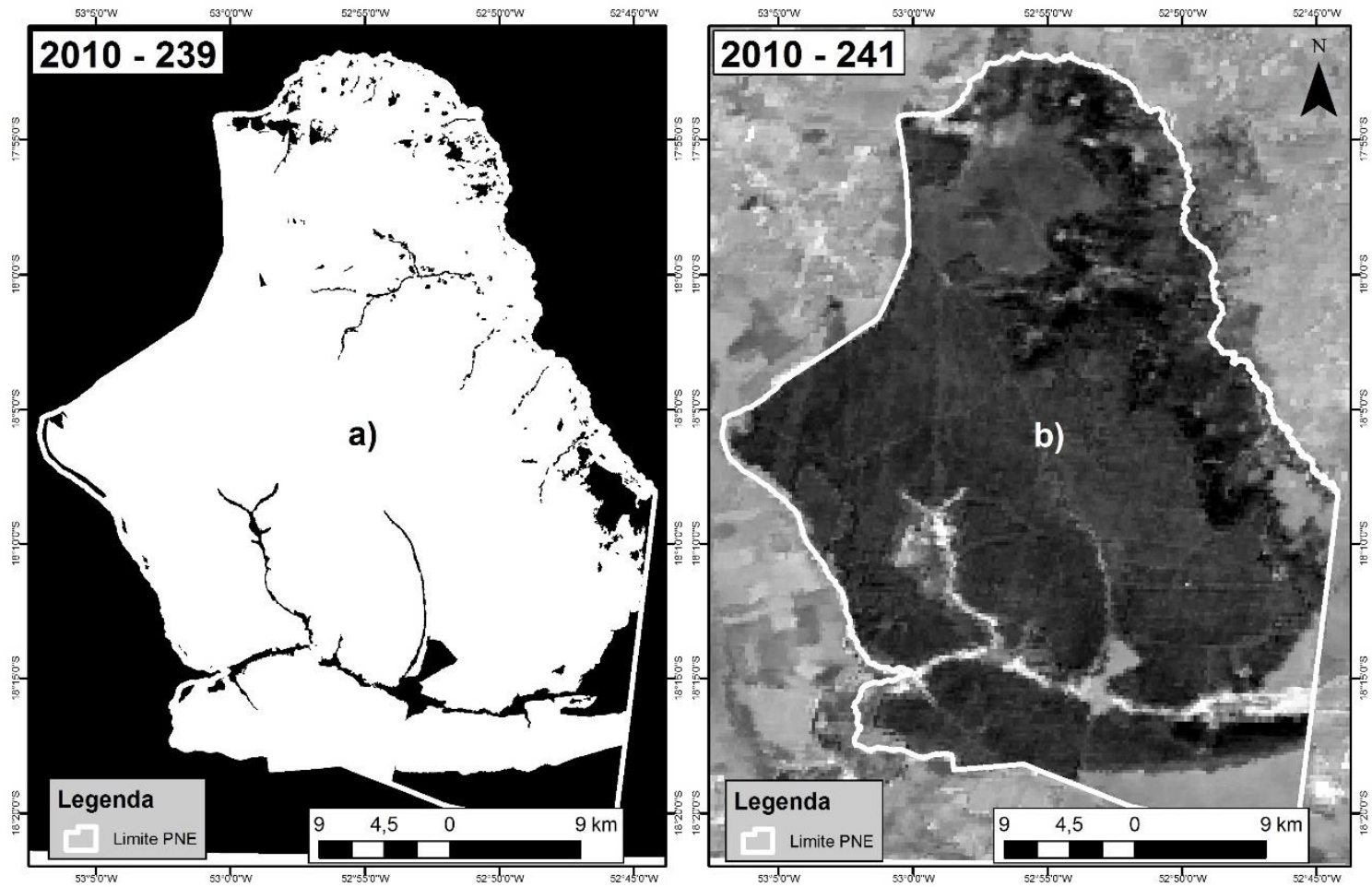

Figura 11. Classificação usada como imagem-verdade na determinação do limiar ótimo (a) e imagem normalizada (nmNBR) utilizada na comparação (b), ano 2010.
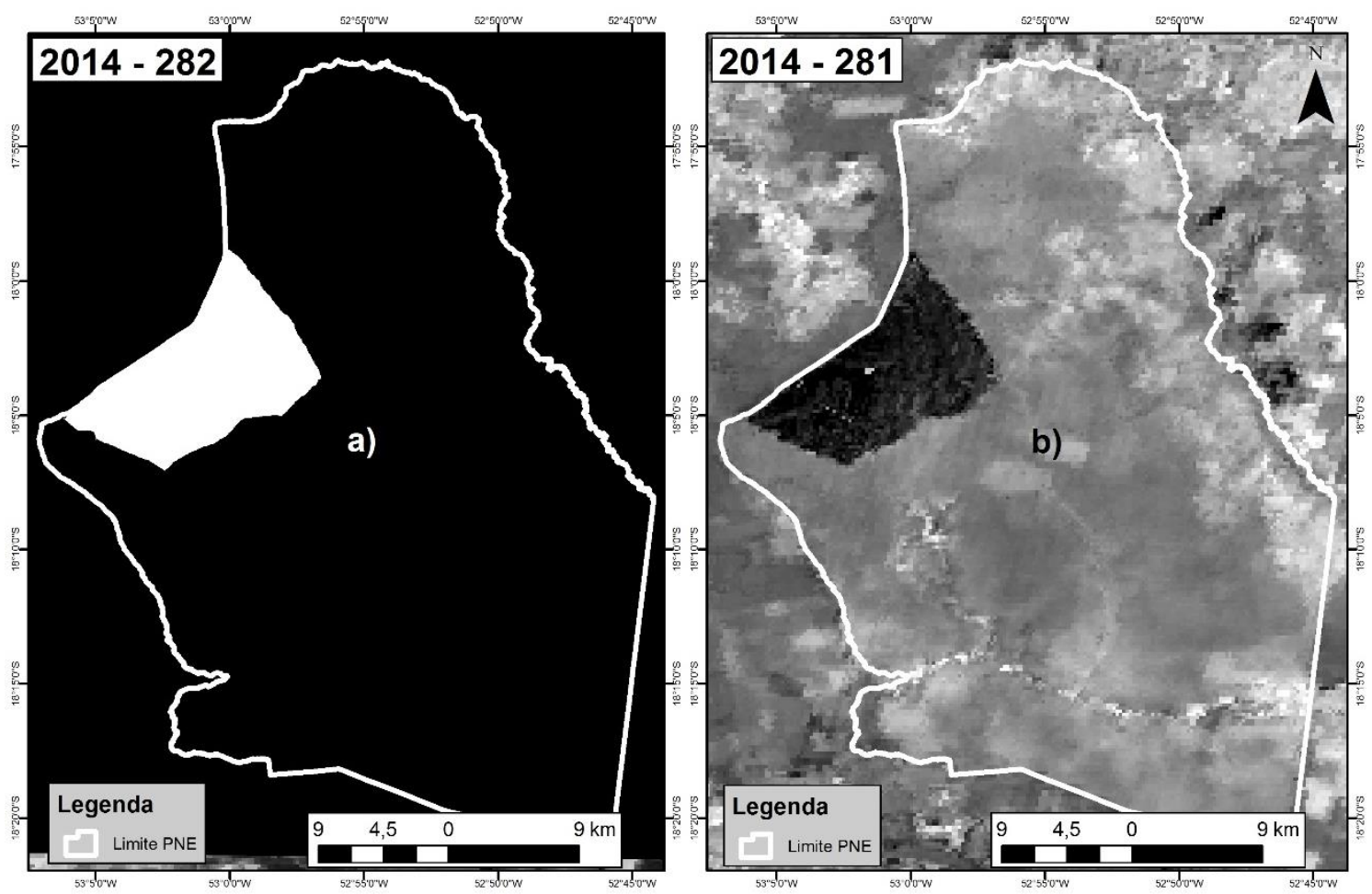

Figura 12. Classificação usada como imagem-verdade na determinação do limiar ótimo (a) e imagem normalizada (nmNBR) utilizada na comparação (b), ano 2014. 


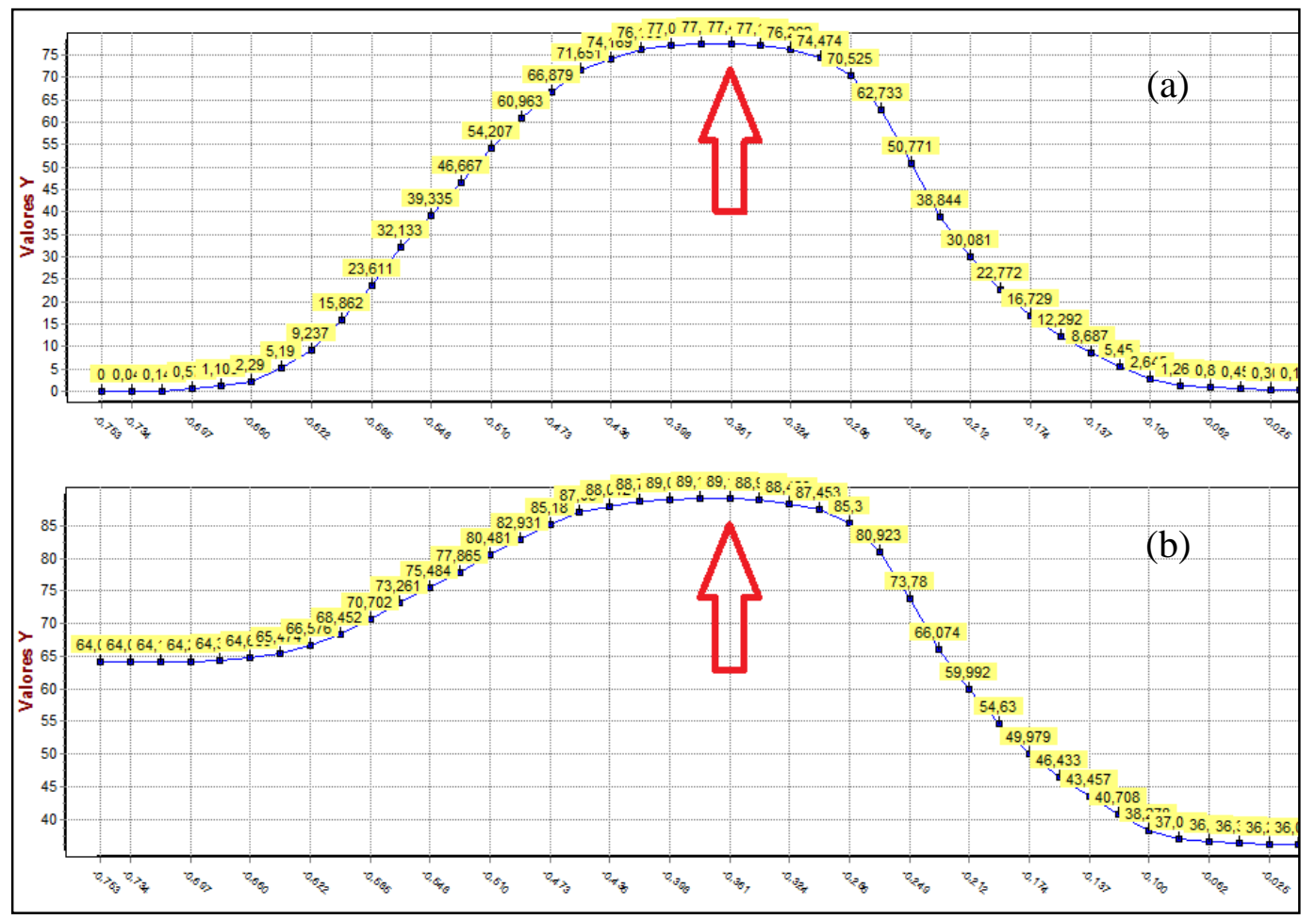

Figura 13. Curvas dos valores do coeficiente Kappa (a) e Overall (b) considerando diferentes valores limites de corte da imagem nmNBR do dia 2005/257.

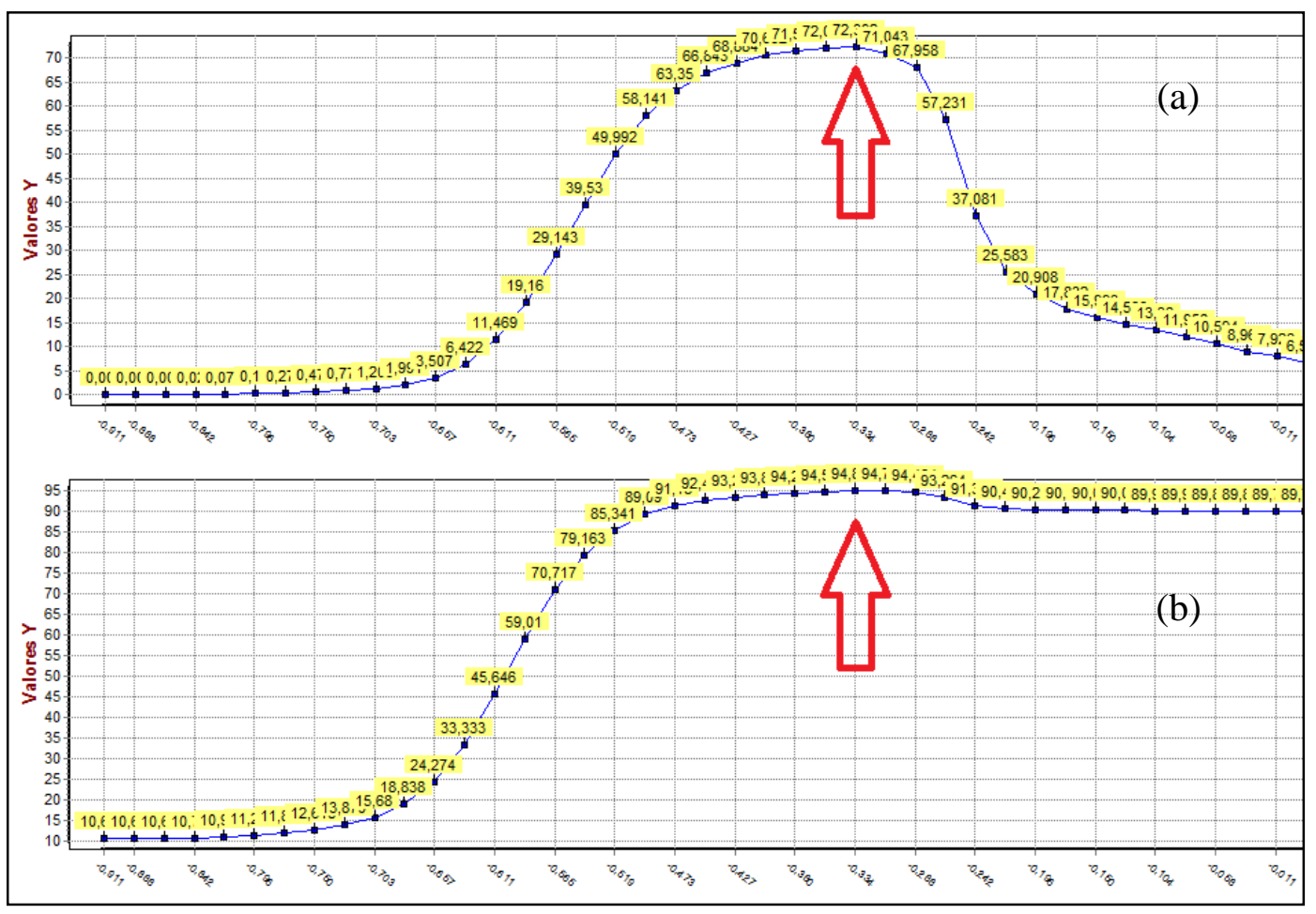

Figura 14. Curvas dos valores do coeficiente Kappa (a) e Overall (b) considerando diferentes valores limites de corte da imagem nmNBR do dia 2010/241. 


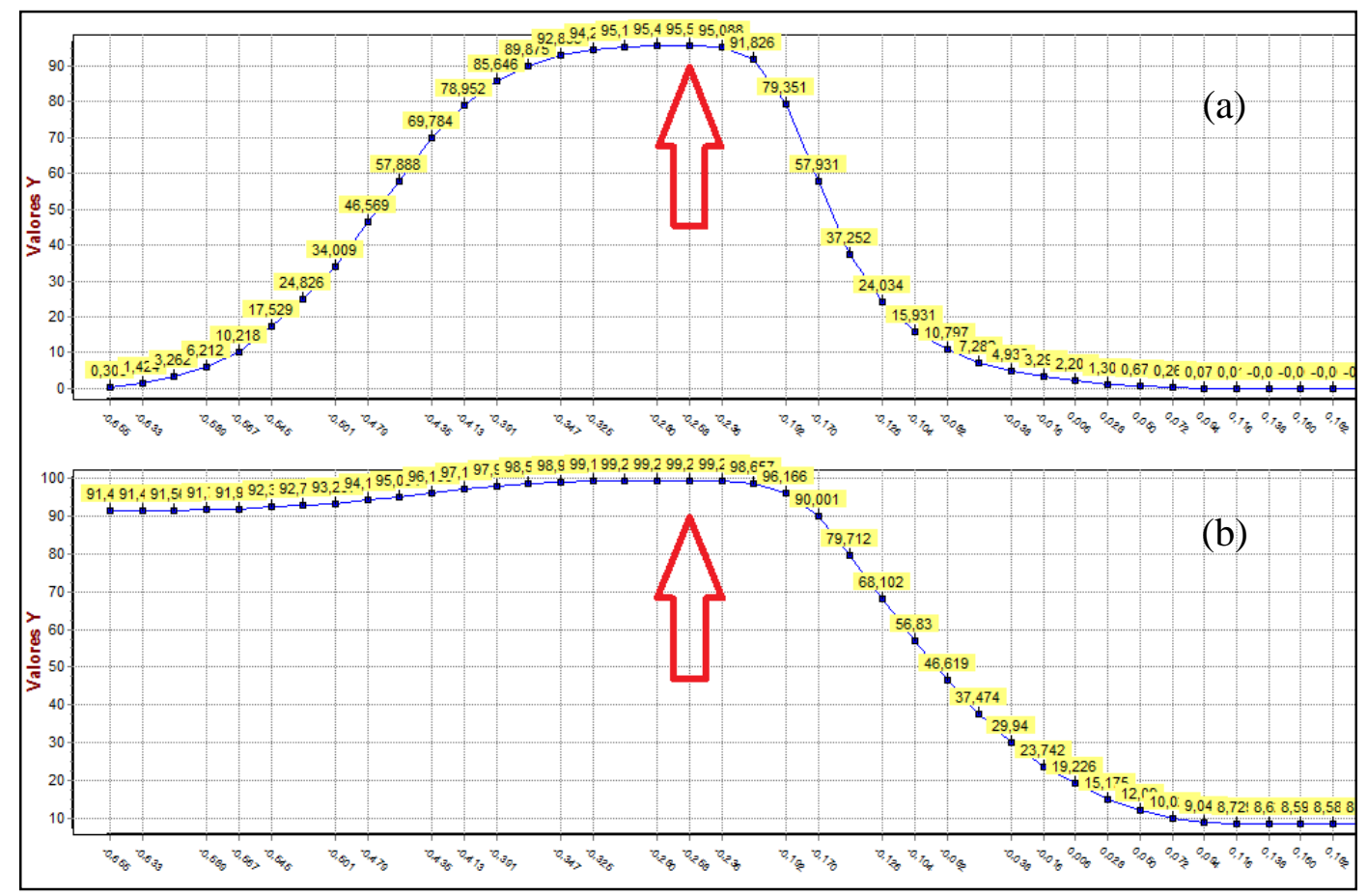

Figura 15. Curvas dos valores do coeficiente Kappa (a) e Overall (b) considerando diferentes valores limites de corte da imagem nmNBR do dia 2014/281.

\subsection{Resultado das Queimadas Anuais no Período 2001-2014 Utilizando os Índices Normalizados MODIS}

As máscaras referentes aos eventos de fogo (644 imagens), extraídas após aplicação do limiar de corte para toda a série temporal, foram aglutinadas em dados anuais (14 imagens). Desta forma, as imagens anuais representaram as áreas que tiveram no mínimo uma detecção de queimada ao longo do ano. A Tabela 2 mostra a dimensão da área queimada para cada ano. Observa-se um percentual médio de 19,4\% de áreas queimadas dentro do PNE. As queimadas de maiores proporções são observadas nos anos de 2005 (48,1\%) e 2010 (91,2\%), que fogem da média observada. O ano de 2011, seguinte ao ano de maior porcentagem de área queimada, apresentou a menor porcentagem de queima $(2,7 \%)$ dentro do período analisado. Os demais anos seguintes $(2012,2013$ e 2014) apresentaram porcentagens variando de 6 a aproximadamente $9 \%$ de área queimada.

Tabela 2. Área de queimada anual no Parque Nacional das Emas no período 2001-2014 utilizando séries temporais nmNBR-MODIS.

\begin{tabular}{|c|c|c|c|c|c|}
\hline Ano & Área (ha) & \% & Ano & Área (ha) & \% \\
\hline $\mathbf{2 0 0 1}$ & $18.161,28$ & 13,7 & $\mathbf{2 0 0 8}$ & $13.102,83$ & 9,9 \\
\hline
\end{tabular}




\begin{tabular}{|c|c|c|c|c|c|}
$\mathbf{2 0 0 2}$ & $27.917,10$ & 21,0 & $\mathbf{2 0 0 9}$ & $15.599,16$ & 11,7 \\
\hline $\mathbf{2 0 0 3}$ & $8.146,80$ & 6,1 & $\mathbf{2 0 1 0}$ & $121.136,22$ & 91,2 \\
\hline $\mathbf{2 0 0 4}$ & $15.396,03$ & 11,6 & $\mathbf{2 0 1 1}$ & $3.531,33$ & 2,7 \\
\hline $\mathbf{2 0 0 5}$ & $63.897,84$ & 48,1 & $\mathbf{2 0 1 2}$ & $8.253,36$ & 6,2 \\
\hline $\mathbf{2 0 0 6}$ & $18.174,33$ & 13,7 & $\mathbf{2 0 1 3}$ & $9.643,41$ & 7,3 \\
\hline $\mathbf{2 0 0 7}$ & $25.854,93$ & 19,5 & $\mathbf{2 0 1 4}$ & $11.780,55$ & 8,9 \\
\hline
\end{tabular}

As imagens anuais demonstraram que $96,3 \%$ do parque queimou no decorrer dos 14 anos analisados. A Tabela 3 lista as recorrências anuais de queimadas entre 2001 e 2014. Nesses dados é possível observar que a maior parte do parque (aproximadamente $75 \%$ ) manteve um baixo regime de recorrência de incêndio, ficando entre uma a três queimadas em todo o período.

Tabela 3. Áreas com recorrência dos eventos de queimadas no Parque Nacional das Emas no período 2001-2014 utilizando séries temporais nmNBR-MODIS.

\begin{tabular}{|c|c|c|c|c|c|}
\hline Ocorrências & Área (ha) & \% & Ocorrências & Área (ha) & \% \\
\hline Sem Ocorrências & 4915,98 & 3,70 & Queimada em 8 anos & 430,38 & 0,32 \\
\hline Queimada em 1 ano & $18.700,02$ & 14,08 & Queimada em 9 anos & 243,54 & 0,18 \\
\hline Queimada em 2 anos & $45.281,52$ & 34,09 & Queimada em 10 anos & 156,42 & 0,12 \\
\hline Queimada em 3 anos & $35.155,62$ & 26,47 & Queimada em 11 anos & 110,61 & 0,08 \\
\hline Queimada em 4 anos & $11.861,64$ & 8,93 & Queimada em 12 anos & 50,94 & 0,04 \\
\hline Queimada em 5 anos & 9661,14 & 7,27 & Queimada em 13 anos & 52,65 & 0,04 \\
\hline Queimada em 6 anos & 3921,3 & 2,95 & Queimada em 14 anos & 23,85 & 0,02 \\
\hline Queimada em 7 anos & 2247,21 & 1,69 & \multicolumn{1}{|l}{} \\
\cline { 1 - 5 }
\end{tabular}

A Figura 16 demonstra a distribuição espacial das ocorrências de queimadas. É possível observar que as maiores recorrências de queimadas ocorrem na faixa oeste do PNE, que faz fronteira com áreas mais antropizadas da circunvizinhança. Esta maior frequência pode ser correlacionada às ações agropecuárias do entorno. Além disso, as ações para a manutenção dos aceiros implantados podem ser grandes responsáveis pela recorrência de queimadas. As áreas centrais do parque mantiveram baixa recorrência de queimadas, ficando em torno de 2 a 3 ocorrências em todo o período analisado, provavelmente por serem áreas mais protegidas de fatores externos. As áreas em que ocorreram queimadas em mais de nove anos dentro do período analisado correspondem 
à pequenos locais próximos à fronteira oeste do parque. Por conta do tamanho em área que ocupam, possuem pouca visibilidade no mapa demonstrado abaixo.

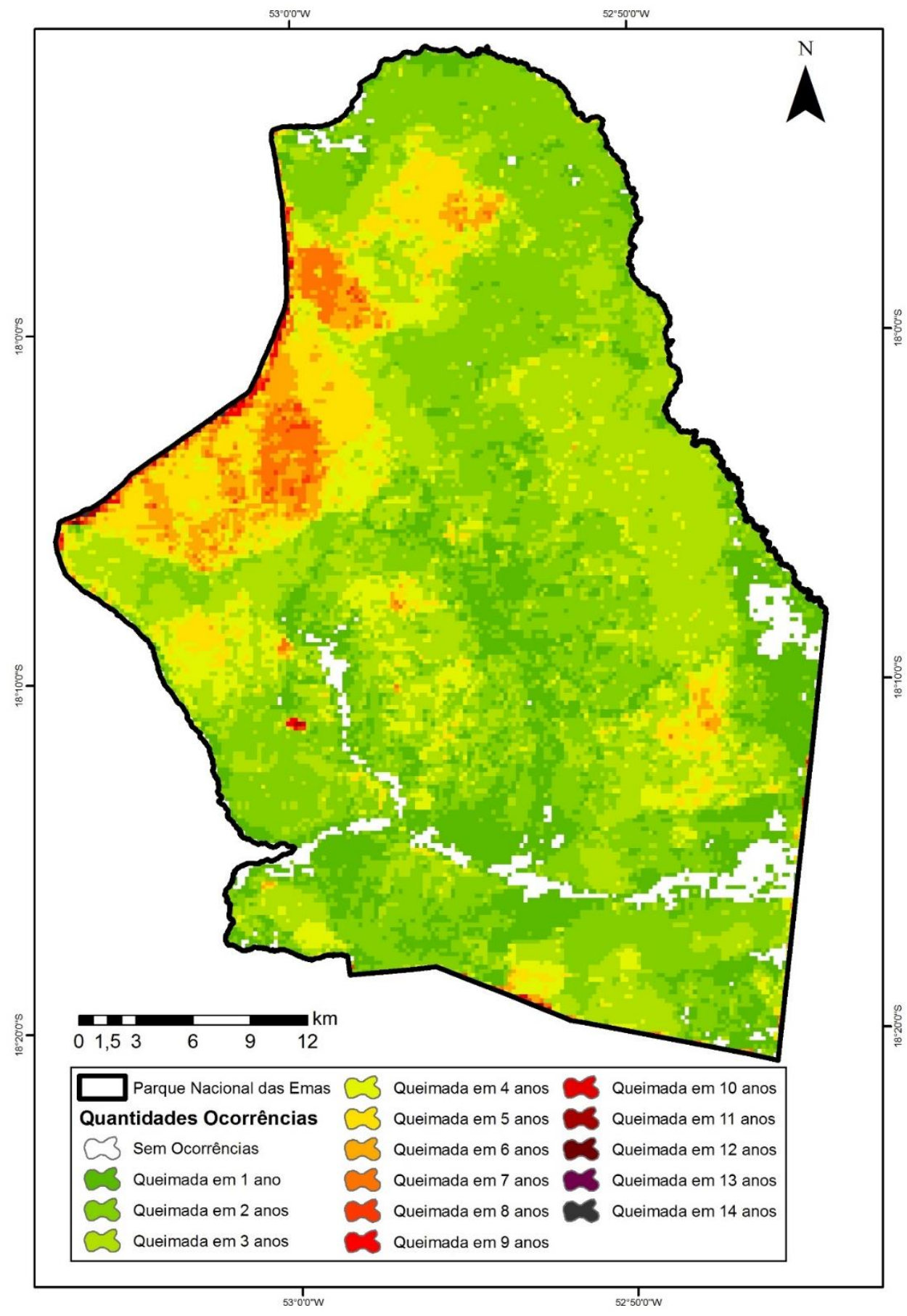

Figura 16. Mapa das ocorrências anuais de queimadas para o Parque Nacional das Emas utilizando séries temporais nmNBR-MODIS. 


\subsection{Resultado das Queimadas entre 2001 e 2014 (Base Referência)}

A maior precisão espacial do mapeamento LANDSAT e Resourcesat permitiu um levantamento mais detalhado da área queimada no PNE para os dias contendo informações. A Tabela 4 lista a quantidade de área queimada no PNE para cada ano utilizando a metodologia descrita. É possível observar uma diminuição de eventos anuais de queimadas no interior do PNE em relação aos dados MODIS, ocorrendo um predomínio de ocorrências com porcentagens abaixo de $10 \%$ da área total. Além disso, foram gerados também mapas com as indicações dos meses de ocorrência de áreas queimadas dentro do parque ao longo de cada ano. Tais informações podem contribuir para uma melhor avaliação da dinâmica de queimada do parque, podendo ser observadas informações como distribuição temporal dos incêndios (período seco ou chuvoso) e também distribuição espacial, ao se considerar o tamanho dos polígonos e local de ocorrência dentro do parque (Figuras 17, 18, 19 e 20).

Tabela 4. Área de queimada anual no Parque Nacional das Emas no período 2001-2014 utilizando imagens temporais dos sensores TM-LANDSAT 5, LANDSAT-8/OLI e Resourcesat.

\begin{tabular}{|c|c|c|c|c|c|}
\hline Ano & Área (ha) & $\mathbf{~ \% ~}$ & Ano & Área (ha) & \% \\
\hline $\mathbf{2 0 0 1}$ & $16.962,80$ & 12,8 & $\mathbf{2 0 0 8}$ & $1.128,30$ & 0,8 \\
\hline $\mathbf{2 0 0 2}$ & $3.111,10$ & 2,3 & $\mathbf{2 0 0 9}$ & $6.516,20$ & 4,9 \\
\hline $\mathbf{2 0 0 3}$ & $4.910,30$ & 3,7 & $\mathbf{2 0 1 0}$ & $118.818,40$ & 89,5 \\
\hline $\mathbf{2 0 0 4}$ & $18.053,70$ & 13,6 & $\mathbf{2 0 1 1}$ & $3.504,00$ & 2,6 \\
\hline $\mathbf{2 0 0 5}$ & $50.811,50$ & 38,3 & $\mathbf{2 0 1 2}$ & $8.688,00$ & 6,5 \\
\hline $\mathbf{2 0 0 6}$ & $23.519,90$ & 17,7 & $\mathbf{2 0 1 3}$ & $1.840,50$ & 1,4 \\
\hline $\mathbf{2 0 0 7}$ & $4.289,60$ & 3,2 & $\mathbf{2 0 1 4}$ & $11.476,90$ & 8,6 \\
\hline
\end{tabular}



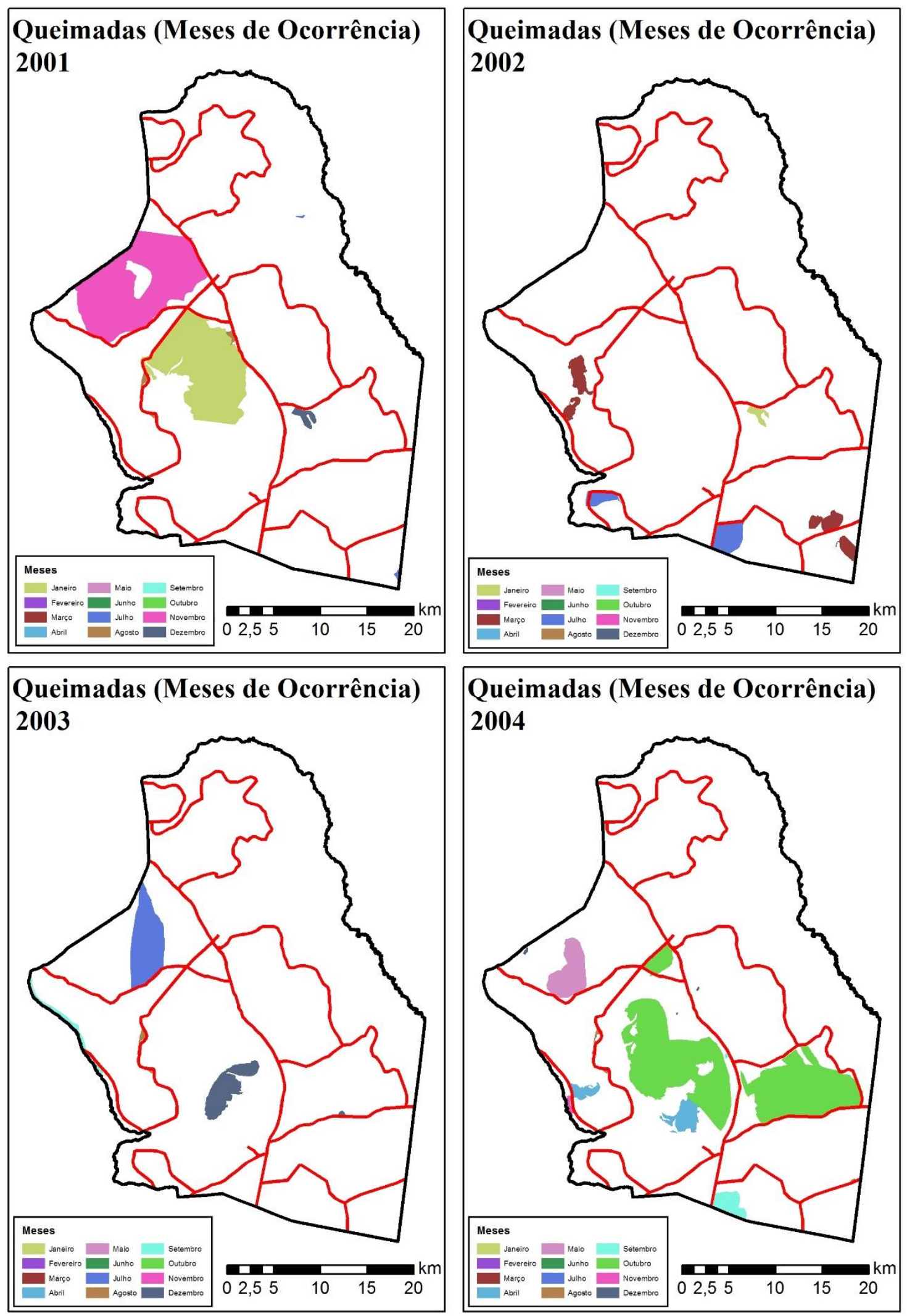

Figura 17. Classificação dos meses de ocorrência de áreas queimadas (2001 - 2004). 

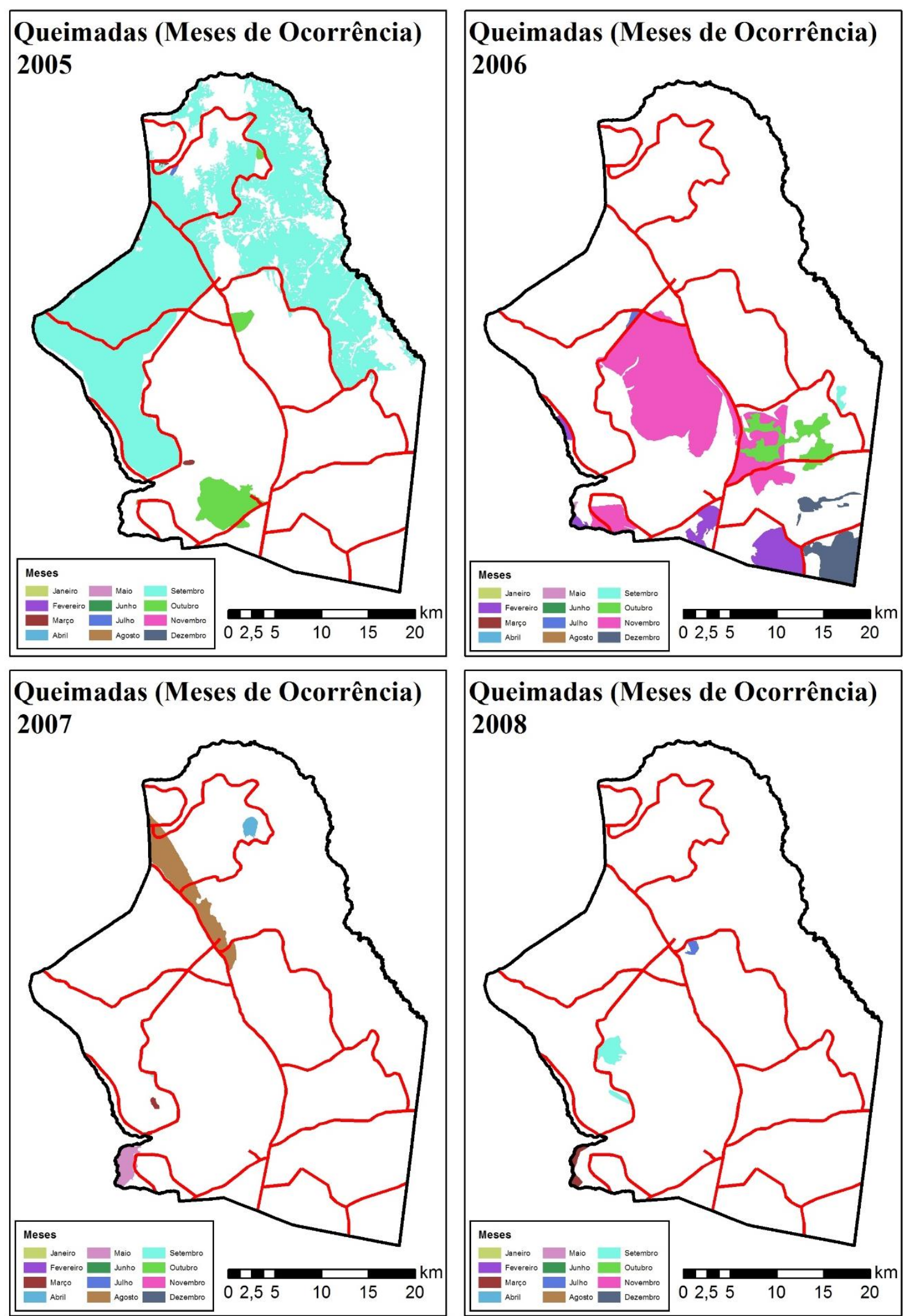

Figura 18. Classificação dos meses de ocorrência de áreas queimadas (2005 - 2008). 

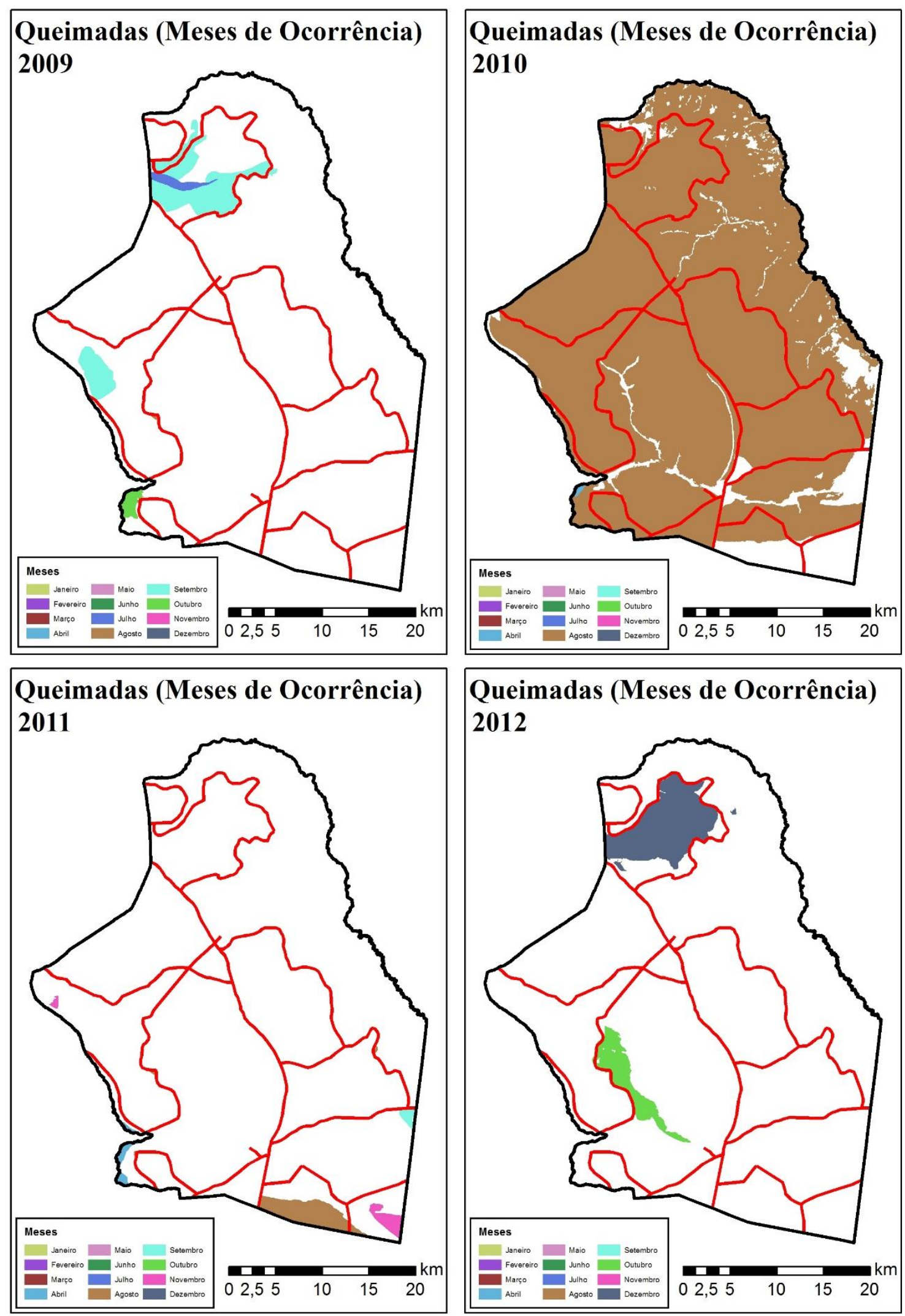

Figura 19. Classificação dos meses de ocorrência de áreas queimadas (2009 - 2012). 

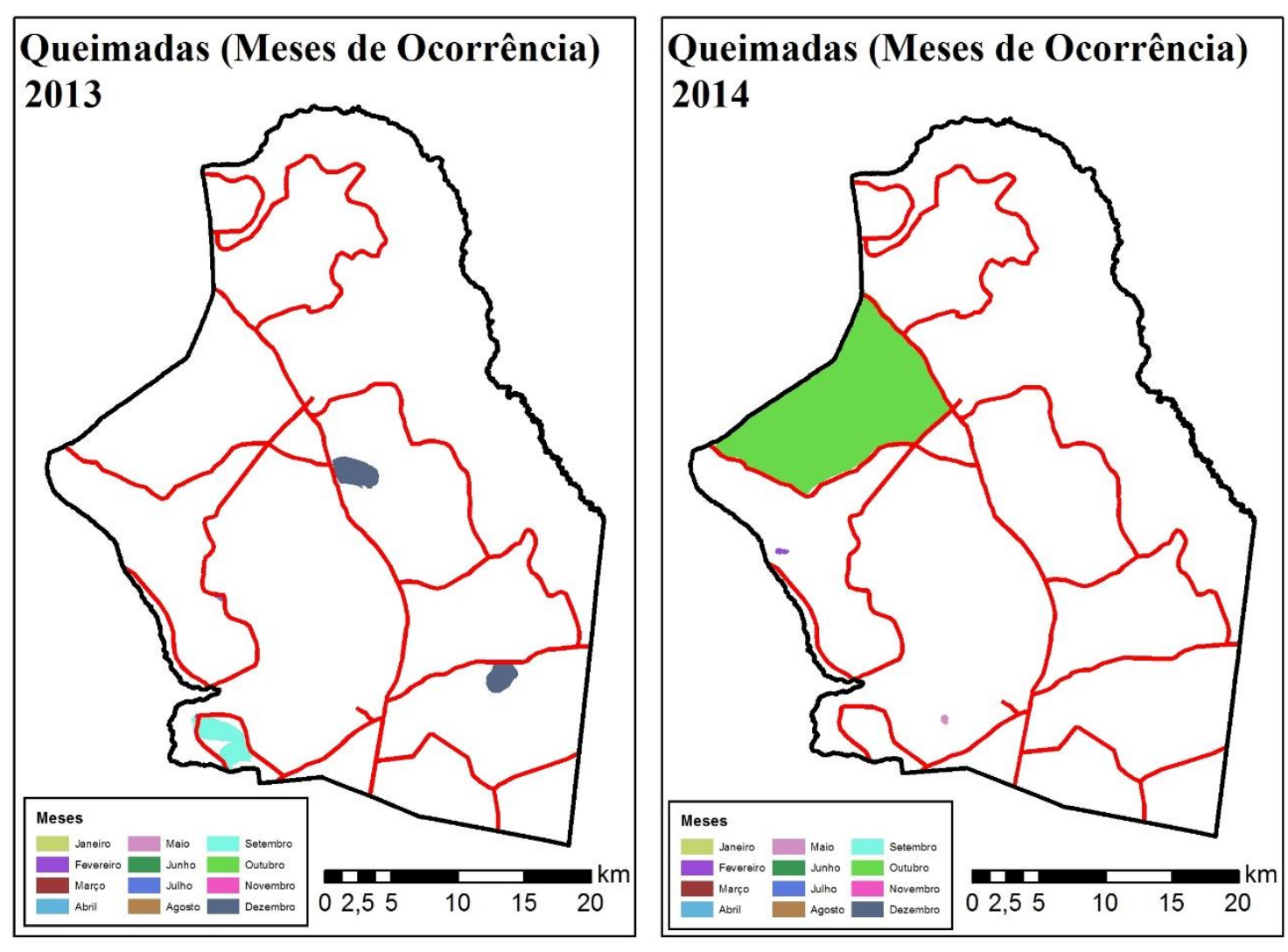

Figura 20. Classificação dos meses de ocorrência de áreas queimadas (2013 - 2014).

A Tabela 5 demonstra as áreas de recorrências de queimadas dentro do limite do PNE usando as imagens discretas no tempo provenientes das imagens TM-LANDSAT 5 LANDSAT-8/OLI e Resourcesat. Durante todo o período, cerca de 120.000 hectares do parque foram queimados, o que corresponde a aproximadamente $94 \%$ da área total.

Tabela 5. Áreas com recorrência anual dos eventos de queimadas no Parque Nacional das Emas no período 2007-2014 utilizando imagens temporais dos sensores TMLANDSAT 5 LANDSAT-8/OLI e Resourcesat.

\begin{tabular}{|c|c|c|c|c|c|}
\hline Ocorrências & Área (ha) & \% & Ocorrências & Área (ha) & \% \\
\hline Sem Ocorrências & $7.772,34$ & 5,9 & Queimada em 5 anos & $5.015,03$ & 3,8 \\
\hline Queimada em 1 ano & $36.799,92$ & 27,7 & Queimada em 6 anos & 44,88 & 0,03 \\
\hline Queimada em 2 anos & $50.403,36$ & 38 & Queimada em 7 anos & 5,27 & 0 \\
\hline Queimada em 3 anos & $21.087,66$ & 15,9 & Queimada em 8 anos & 25,03 & 0,02 \\
\hline Queimada em 4 anos & $11.652,56$ & 8,8 & Queimada em 9 anos & 5,36 & 0 \\
\hline
\end{tabular}

A Figura 21 mostra a localização das recorrências de queimadas dentro do parque ao longo dos 14 anos analisados. As maiores ocorrências, assim como no mapeamento 
MODIS, são observadas na parte oeste do parque, próximo à divisa, onde as atividades agropecuárias próximas ou até mesmo as ações de manejo do fogo por aceiros podem ter impacto significativo nesse resultado. Em contraposição, nesse mapeamento é notável que a faixa leste do PNE, além das áreas centrais, possui baixa recorrência de incêndios, já que a limitação pelo Rio Jacuba gera uma barreira natural que auxilia na redução de influências externas no processo de queimadas do PNE.

No período 2001-2014 foram mapeados 109 polígonos de queimadas (Tabela 6). Os maiores eventos de queimadas ocorreram em 2005 (38,3\%) e $2010(89,5 \%)$ durante o período de seca. FRANÇA et al. (2004) e PEREIRA \& FRANÇA (2005) avaliaram a nova dinâmica de queimadas do parque como sendo resultante principalmente da incidência de raios no período chuvoso. A análise dos dados abaixo demonstram proximidade nos totais de focos de queimadas no interior do parque entre os períodos secos e chuvosos. Com isso, embora tenha ocorrido diminuição na área de extensão das queimadas dentro do parque, ainda ocorrem eventos na mesma proporção tanto no período seco quanto chuvoso, o que pode indicar a continuidade tanto das ocorrências naturais quanto antrópicas ao longo do ano.

Tabela 6. Distribuição temporal dos focos de incêndio do Parque Nacional das Emas considerando as imagens temporais dos sensores TM-LANDSAT 5 LANDSAT-8/OLI e Resourcesat.

\begin{tabular}{|c|c|c|c|c|c|}
\hline \multirow{2}{*}{ Período } & Mai/Set & Out/Abr & \multirow{2}{*}{ Período } & Mai/Set & Out/Abr \\
\cline { 6 - 6 } & $\mathbf{N}^{\mathbf{0}}$ & $\mathbf{N}^{\mathbf{0}}$ & & $\mathbf{N}^{\mathbf{0}}$ & $\mathbf{N}^{\mathbf{0}}$ \\
\hline 2001 & 5 & 3 & 2008 & 3 & 1 \\
\hline 2002 & 2 & 5 & 2009 & 6 & 1 \\
\hline 2003 & 4 & 2 & 2010 & 2 & 1 \\
\hline 2004 & 6 & 10 & 2011 & 5 & 5 \\
\hline 2005 & 10 & 6 & 2012 & - & 3 \\
\hline 2006 & 3 & 12 & 2013 & 3 & 2 \\
\hline 2007 & 3 & 3 & 2014 & 1 & 2 \\
\hline Totais & 33 & 41 & Totais & 20 & 15 \\
\hline
\end{tabular}




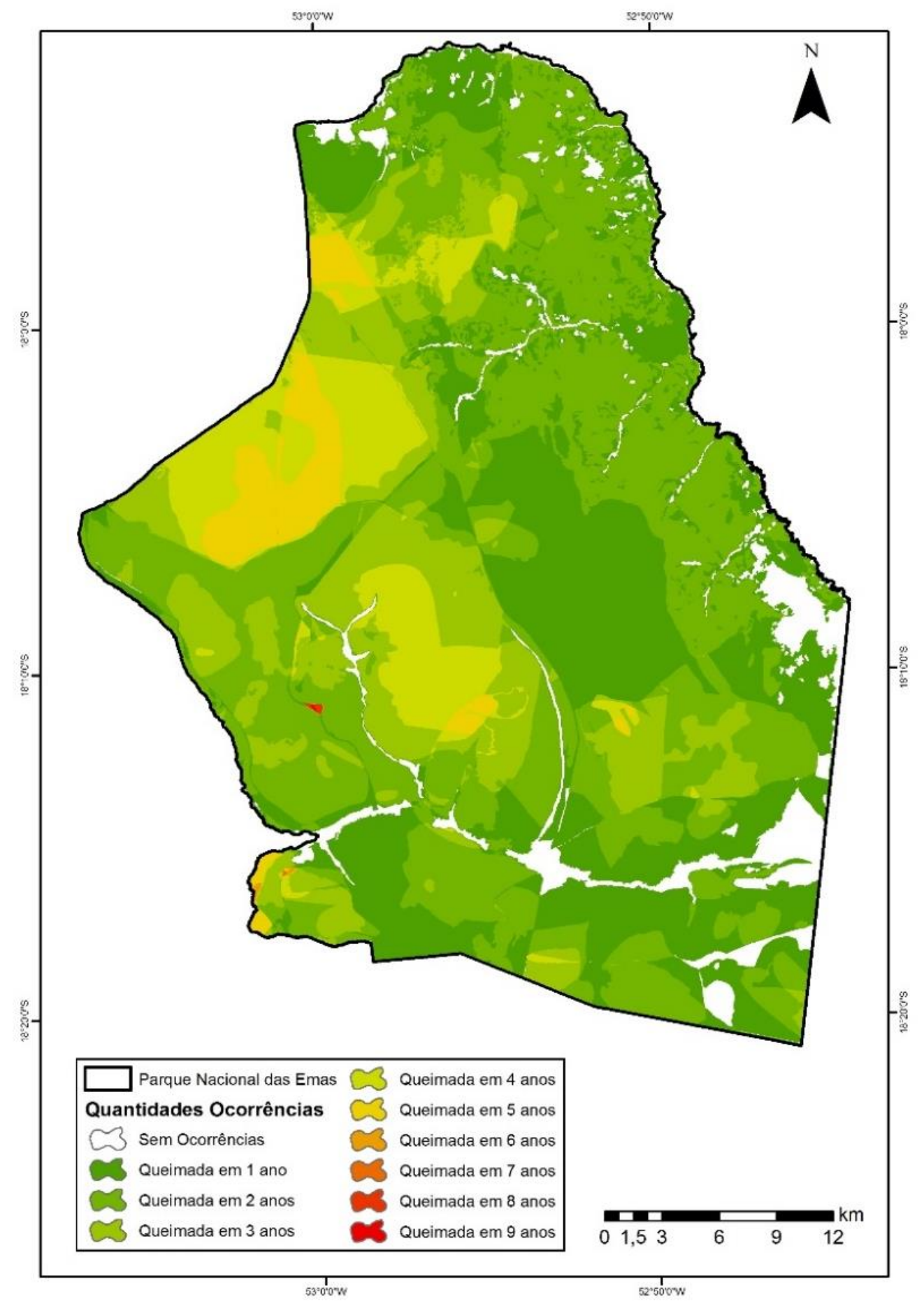

Figura 21. Mapa das ocorrências anuais de queimadas para o Parque Nacional das Emas utilizando imagens temporais dos sensores TM-LANDSAT 5 LANDSAT-8/OLI e Resourcesat.

Uma avaliação do histórico de queimadas demonstra também a significativa diminuição das extensões de queimadas no interior do parque. Mesmo o ciclo de recorrências de grandes queimadas identificado por França et al. (2007) em intervalos de três anos foi modificado após as ações adotadas a partir de 1994 (Figura 22). 


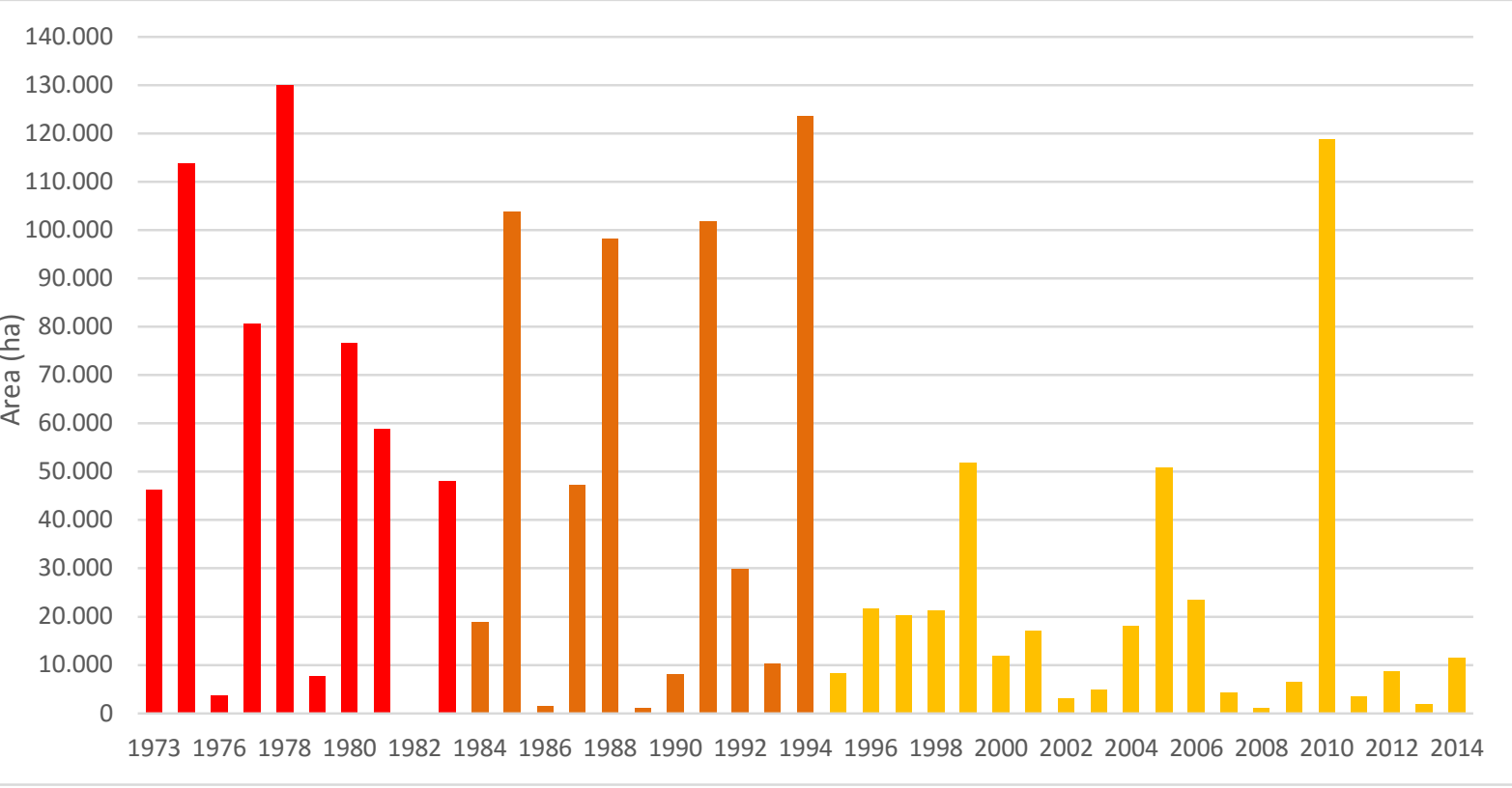

Figura 22. Histórico de queimadas do PNE. Fonte dos dados até 2003 - França et al. (2007).

No levantamento histórico da ocorrência do fogo no PNE, França et al (2007) identificaram três períodos dessas ocorrências. Tais períodos são bem visíveis no gráfico acima, que mostra a ocorrência de grandes e contínuos incêndios no período de 1973 a 1983 (primeiro período), onde grande parte da área do parque era utilizada para pastagens e sofria queimadas intencionais para rebrota da vegetação. Entre 1984 e 1994 (segundo período), mesmo com a retirada do gado do interior do parque, as influências externas das atividades agropecuárias tiveram forte impacto na dinâmica do fogo. Nesse período é bem evidente o ciclo de grandes queimadas a cada três anos. De um modo geral, a partir de 1994 (terceiro período) as ocorrências de queimadas no parque diminuiram significativamente, o que sugere um equilíbrio entre a ocorrência natural do fogo e a efetividade das ações de manejo implementadas pela gestão do parque.

\subsection{Comparação Base MODIS x Referência}

A comparação dos dados MODIS e o mapeamento de referência permitiu avaliar a eficiência do método de identificação das áreas queimadas. Todas as áreas mapeadas por meio de imagens LANDSAT e Resourcesat aparecem nos mapeamentos MODIS, entretanto, esse último considera novas áreas, visto que possui uma maior resolução temporal e maior disponibilidade de dados, além de possibilitar o mapeamento em áreas eventualmente cobertas por nuvens nas bases de referência. Com isso, é notável a diferença na quantificação das áreas observadas nos dois mapeamentos. 
São mostradas abaixo duas situações incorporadas pelos dados MODIS e que favorecem as discrepâncias entre os dois mapeamentos: 1) Áreas não observadas na base de referência por indisponibilidade de cobertura de imagens; 2) Áreas não observadas na base de referência por cobertura de nuvens.

Como os satélites LANDSAT e Resourcesat possuem resolução temporal de 16 e 24 dias, respectivamente, existe a possibilidade da ocorrência de queimadas nos intervalos de passagem, tornando mais difíceis as visualizações. Em alguns casos, a recuperação da vegetação se dá de forma tão acelerada que torna as cicatrizes de queimadas imperceptíveis na comparação entre a imagem anterior e posterior ao evento. Em outras situações, por problemas técnicos do sensor, por exemplo, há interrupção do fornecimento das imagens, impossibilitando o mapeamento de referência.

No ano de 2007, por exemplo, houve interrupção no fornecimento das imagens LANDSAT no mês de setembro, retornando somente no ano seguinte. Dessa forma, as ocorrências de queimadas nos últimos meses do ano não puderam ser mapeadas por esse sensor. A Figura 23 mostra uma sequência de imagens MODIS (22/09, 30/09, 08/10, 16/10) onde há ocorrência de dois focos nítidos de queimadas e que não são observáveis na última imagem LANDSAT disponível (20/09) para o determinado ano. As imagens mostram também a rápida recuperação da vegetação em um dos focos, aspecto esse que pode dificultar o mapeamento. 

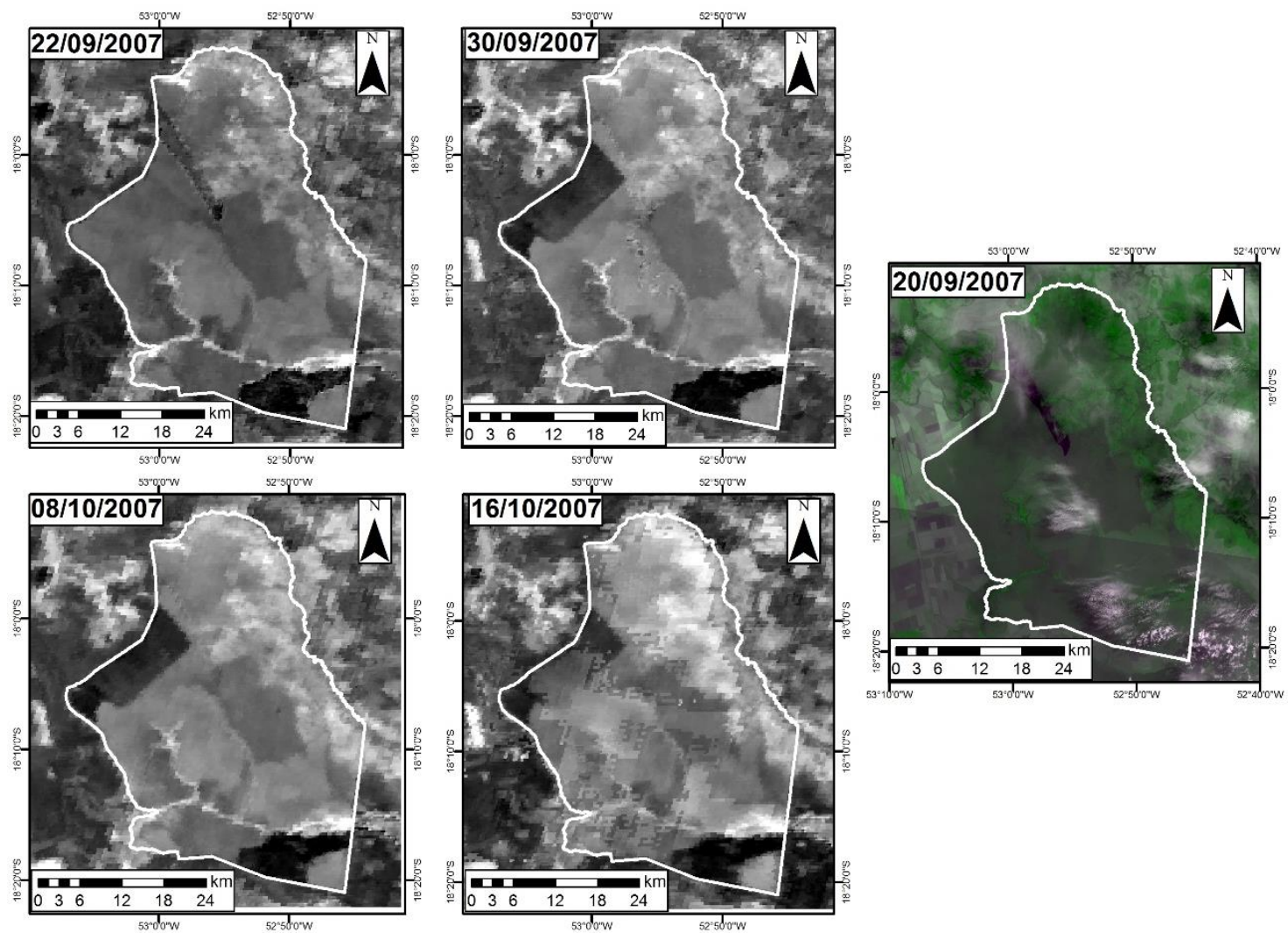

Figura 23. Sequência de imagens MODIS evidenciando áreas queimadas não mapeadas na base de referência por indiponibilidade de imagens LANDSAT ou Resourcesat.

A segunda situação que favorece a discrepância das quantificações é a cobertura de nuvens nas imagens de referência. Com a maior resolução temporal MODIS, aumentam as possibilidades de captura das áreas queimadas sem a ocorrência de nuvens. A Figura 24 mostra uma área do PNE no ano de 2009 recoberta com nuvens na imagem de referência, o que impossibilitou o mapeamento total da área queimada. Percebe-se, por outro lado, o destaque nítido da área queimada na imagem MODIS, sem nenhuma interferência por nuvens. 

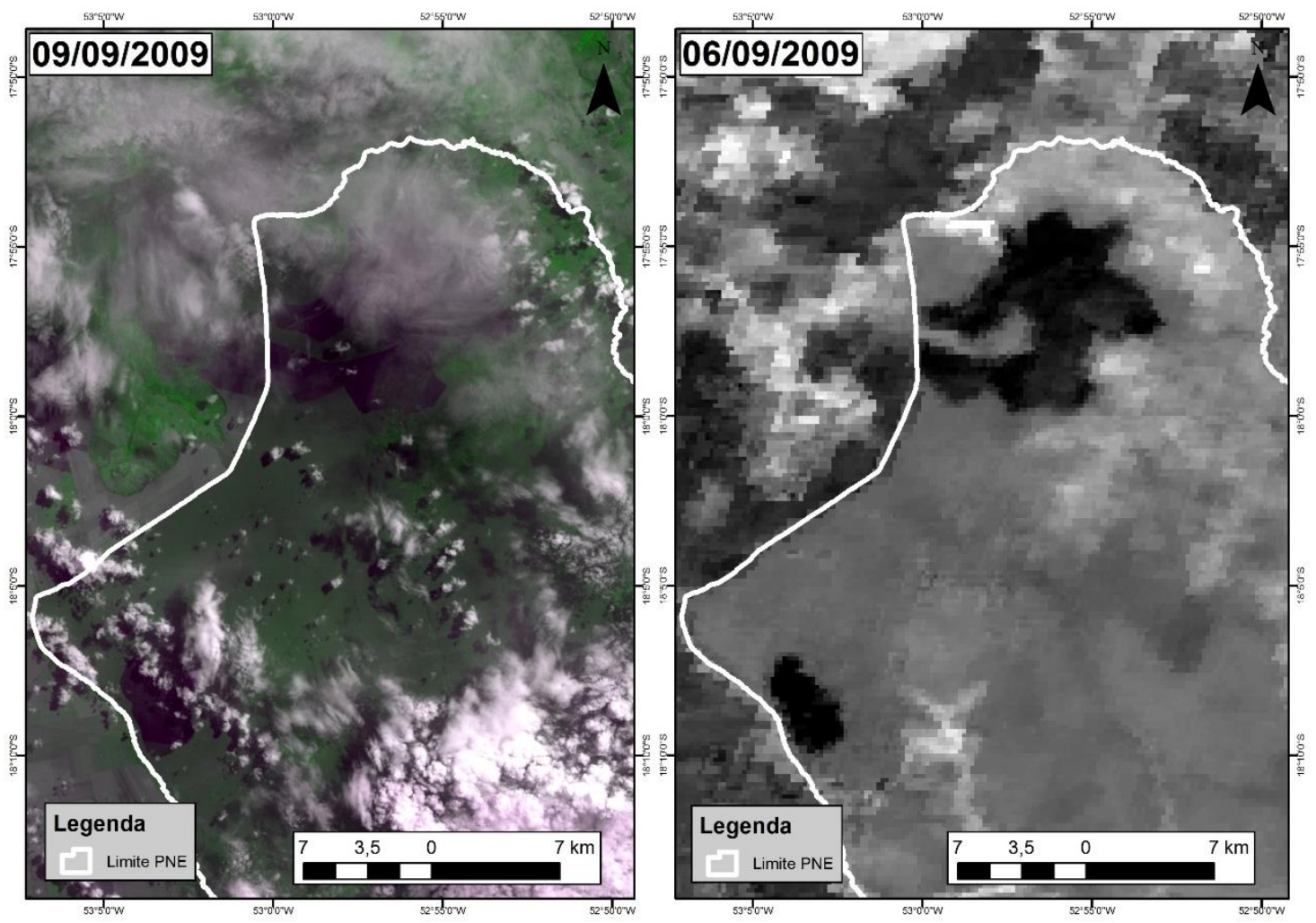

Figura 24. Áreas queimadas não mapeadas na base de referência por excessiva cobertura de nuvens.

A comparação dos mapeamentos de queimadas por ano mostra a eficiência do método na delimitação precisa das áreas, tomando por base os dados para referência e extrapolando para todas as ocorrências dentro do ano (Figuras 25 e 26). Os coeficientes Kappa e Overall entre cada ano demonstram as similaridades e diferenças. Na Tabela 7 percebe-se uma grande variação nos valores de Kappa. Tal variação é resultante da diferença dos mapeamentos por conta dos motivos já levantados. Nos anos em que a cobertura de nuvens e a indisponibilidade de imagens não foram impeditivas para a montagem da base de referência, além de apresentarem menos resíduos no mapeamento, percebe-se valores altos de acurácia, como por exemplo, nos anos de 2005, 2010, 2011 e 2014. Na análise comparativa entre os somatórios das queimadas nos dois mapeamentos, percebe-se a mesma dinâmica no interior do parque, onde as maiores recorrências de queimadas ocorrem na porção oeste e mais próxima às áreas de alta antropização e as menores nas áreas próximas às barreiras naturais Figura 27. 

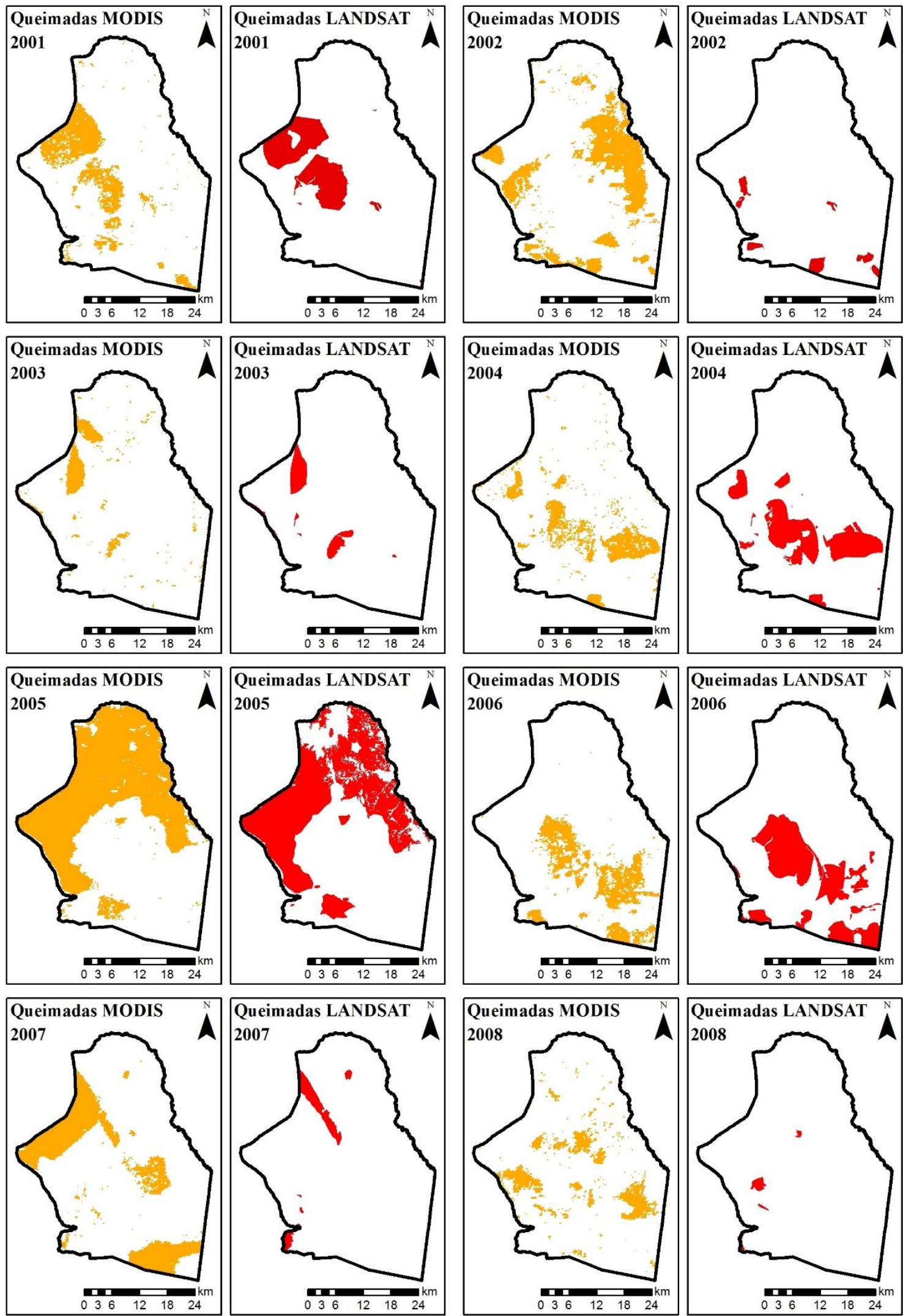

Figura 25. Comparação das recorrências anuais de queimadas no interior do PNE. Mapeamentos MODIS e LANDSAT/Resourcesat - Anos 2001 a 2008. 

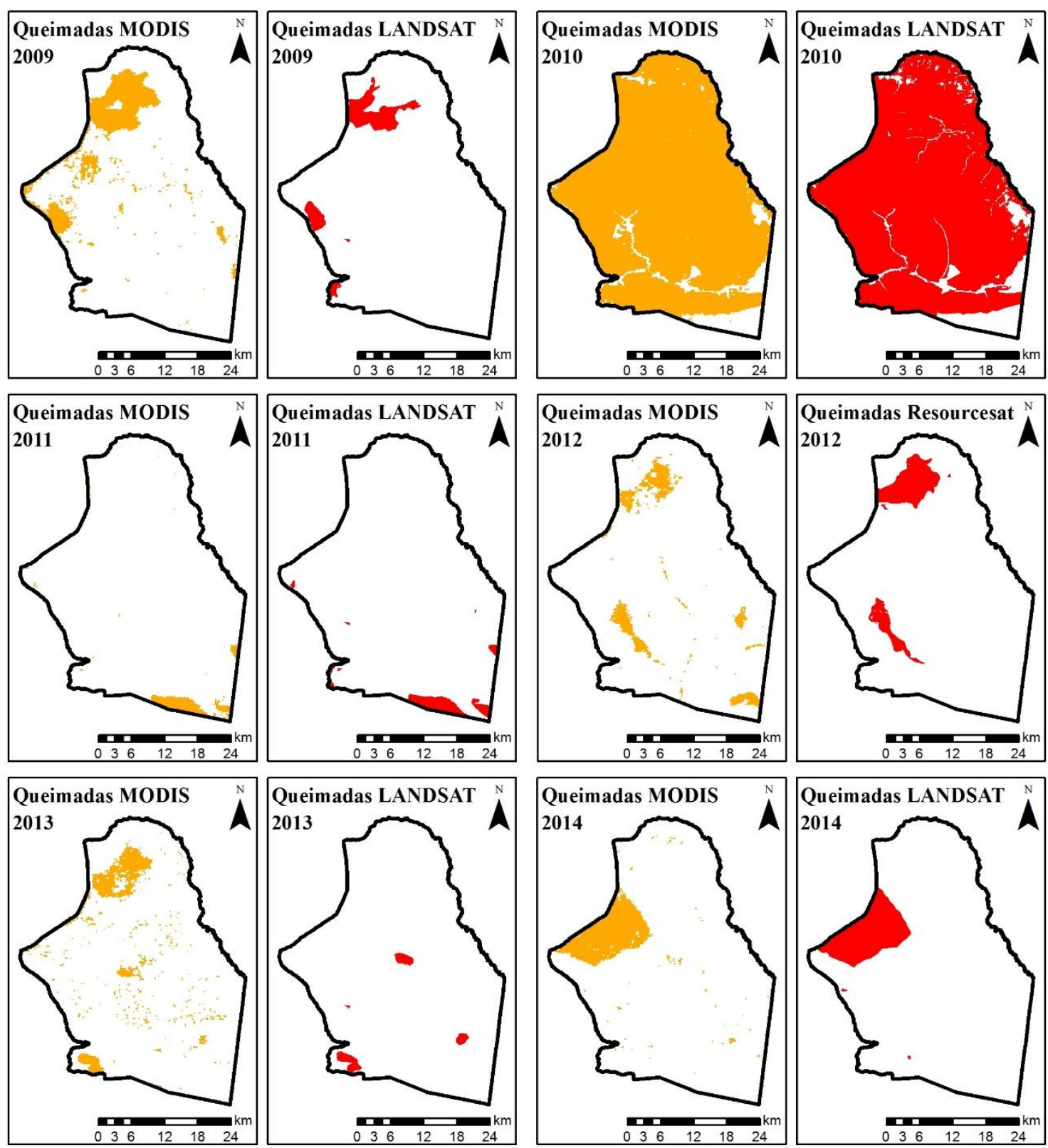

Figura 26. Comparação das recorrências anuais de queimadas no interior do PNE. Mapeamentos MODIS e LANDSAT/Resourcesat - Anos 2009 a 2014. 
Tabela 7. Coeficientes de acurária para cada ano. Comparação base MODIS e LANDSAT/Resoucesat.

\begin{tabular}{|c|c|c|c|c|c|}
\hline Anos & Kappa & Overall & Anos & Kappa & Overall \\
\hline $\mathbf{2 0 0 1}$ & 0,6799 & 96,8172 & $\mathbf{2 0 0 8}$ & 0,0841 & 96,1258 \\
\hline $\mathbf{2 0 0 2}$ & 0,1246 & 92,0107 & $\mathbf{2 0 0 9}$ & 0,5148 & 96,8787 \\
\hline $\mathbf{2 0 0 3}$ & 0,5854 & 98,4099 & $\mathbf{2 0 1 0}$ & 0,9547 & 97,9163 \\
\hline $\mathbf{2 0 0 4}$ & 0,6953 & 97,1022 & $\mathbf{2 0 1 1}$ & 0,7735 & 99,527 \\
\hline $\mathbf{2 0 0 5}$ & 0,8239 & 94,981 & $\mathbf{2 0 1 2}$ & 0,5772 & 97,9117 \\
\hline $\mathbf{2 0 0 6}$ & 0,6446 & 95,8398 & $\mathbf{2 0 1 3}$ & 0,1897 & 97,242 \\
\hline $\mathbf{2 0 0 7}$ & 0,216 & 93,092 & $\mathbf{2 0 1 4}$ & 0,9197 & 99,4608 \\
\hline
\end{tabular}

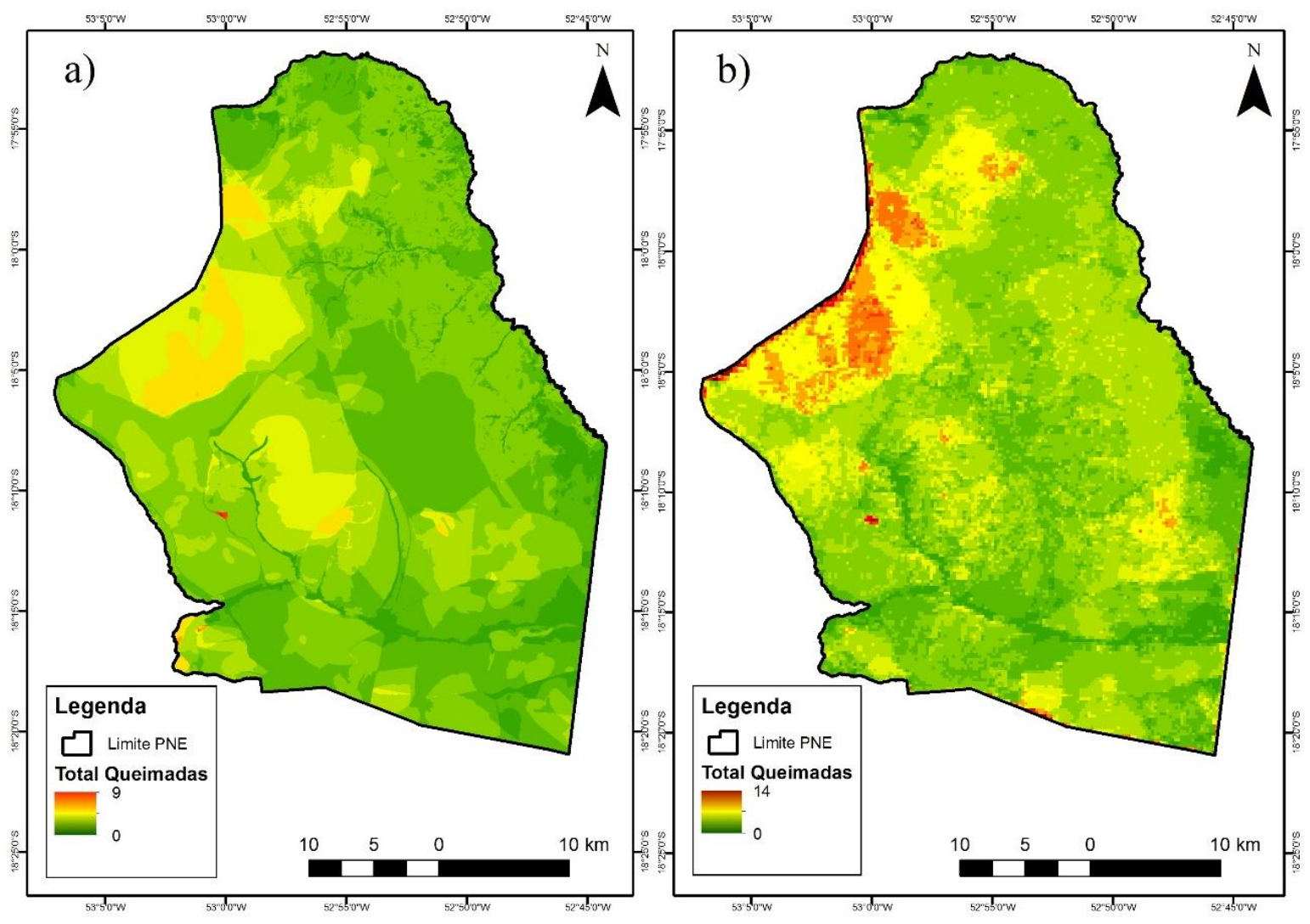

Figura 27. Comparação dos somatórios de áreas queimadas no interior do PNE. Base de referência (a) e base MODIS (b). 


\section{DISCUSSÃO}

O NBR é um dos índices com maior utilização na identificação de áreas queimadas. Além da utilização para avaliação da severidade das queimadas, é também frequentemente usado em técnicas de deteç̧ão de mudanças, como o dNBR, por exemplo, com o propósito de evidenciar as áreas queimadas (MILLER \& THODE, 2007; VERAVERBEKE et al., 2012). O NBR em comparação com o NDVI demonstra um perfil com menores variações do sinal, dando destaque para os picos de mínima, que normalmente sinalizam queimadas. $\mathrm{O}$ mapeamento de queimadas utilizando séries temporais, possui a vantagem de uma análise da dinâmica do fogo na área estudada. Porém, como são extraídas informações de uma sequência de imagens, pode estar suscetível a propagação de erros (CARVALHO JÚNIOR et al., 2015).

A utilização do filtro Savitzky-Golay foi escolhida pela conjução dos aspectos de tratamento dos ruídos e suavização do perfil espectral e também pela característica de manutenção dos picos no perfil, tanto de máxima como de mínima (CHEN et al., 2004). Essa característica potencializa a extração de áreas queimadas pelo perfil, uma vez que a ocorrência do fogo e suas consequências, como o consumo de matéria orgânica e depósito de cinzas, por exemplo, gera uma queda abrupta no sinal, formando picos. Outros filtros utilizados em séries temporais como Mediana, Minimum Noise Fraction ou Fourier (CARVALHO JÚNIOR, HERMUCHE \& GUIMARÃES, 2006; CARVALHO JÚNIOR et al., 2012), garantem a suavização do espectro e tratamento dos ruídos, porém tem impacto no formato dos picos, podendo achatá-los ou reduzir a dimensionalidade por meio de processos de interpolação.

A aplicação da normalização pela Média na presente pesquisa teve como objetivo um maior destaque visual às áreas queimadas e também a padronização dos diferentes valores de NBR encontrados por conta da variação de fitofisionomias do Cerrado. Embora grande parte do parque apresente feições campestres, os restantes das fitofisionomias encontradas geram uma disparidade de valores que poderia dificultar a determinação de um único limiar para o mapeamento das áreas queimadas. Dessa forma, a normalização pela Média possibilitou a comparação entre as fitofisionomias. Carvalho Júnior et al. (2015) utilizaram a normalização pelo método Z-Score para o destaque das áreas queimadas e padronização dos valores NBR nas diferentes fisionomias de Cerrado. Entretanto, verificou-se que a aplicação do Z-Score em dados NBR pode estar suscetível 
a erros de classificação em áreas com maior quantidade de umidade. Dessa forma, Matas Ciliares e de Galeria, ou locais com maior densidade de linhas de drenagem podem apresentar confusões com áreas queimadas.

Diversos trabalhos se utilizam da definição de um limiar para o mapeamento de queimadas. A aplicação em dados NBR, dNBR, NDVI ou outros dados possibilita a separação das áreas queimadas quando o valor do pixel ultrapassa o valor do limiar (LOBODA et al., 2007). O presente trabalho utilizou-se de uma metodologia de identificação do melhor limiar através da comparação com dados LANDSAT e ResourceSat, assumidos aqui como mapeamento de referência. O programa utilizado para a extração do melhor limiar (Abílio) realizou a comparação entre a imagem nmNBRMODIS e o mapeamento das áreas queimadas realizado com imagens LANDSAT e ResourceSat, definindo o melhor valor limite para extração das áreas queimadas a partir de índices de acurácia. Em comparação aos trabalhos de Chuvieco et al. (2008), Miller et al. (2009) ou Veraverbeke et al. (2010) que definiram os valores de limiar para a extração das áreas queimadas de forma empírica, esse procedimento minimiza a subjetividade na determinação dos limiares, além de garantir rapidez e segurança nos resultados. O melhor limiar obtido por meio da comparação com imagens discretas foi então aplicado para toda a série temporal como forma de extração das áreas queimadas ao longo de todos os anos estudados. Além disso, é possível a verificação de diferentes limiares por meio de testes em diversas imagens ao longo da série temporal, garantindo a exploração de uma maior diversidade de cenários. Na definição dos melhores valores limite para corte foram obtidos altos níveis de acurácia dos índices Kappa (77,482 em 2005; 72,392 em 2010 e 95,519 em 2014) e Overall (89,141 em 2005; 94,842 em 2010 e 99,295 em 2014). O mapeamento por meio da aplicação do melhor limiar permitiu a individualização das áreas queimadas, que foram comparadas com os dados de referência.

O mapeamento a partir de imagens LANDSAT e ResourceSat permitiu uma primeira avaliação da nova dinâmica de fogo dentro do Parque Nacional das Emas. Em comparação aos dados apresentados por França \& Setzer (1997) e França et al. (2007), percebe-se uma quebra no ciclo de queimadas de três em três anos observados até 1994, bem como uma redução significativa no percentual de área queimada por ano. Entre 1994 e 2003, o novo regime de queimadas mostrou uma significativa diminuição, mantendose entre 10 a $30 \%$ ao ano (França et al., 2007). Os dados aqui apresentados mostram 
também um processo de diminuição de área queimada, onde o percentual médio de queimadas em todo o período estudado é de 19,4\%, mesmo considerando os grande eventos ocorridos em 2005 e 2010. De um modo geral, o percentual de área queimada dentro do PNE em cada ano tem se mantido abaixo de $15 \%$. A distribuição espaçotemporal das áreas queimadas no interior do parque mostra um equilíbrio do número de focos tanto no período seco quanto chuvoso, embora as dimensões das queimadas possam ser mais extensas no período seco (como nos anos 2005 e 2010). É também possível analisar a importância da barreira formada pela rede de aceiros, uma vez que a maioria das áreas mapeadas como queimadas compartilha alguma face com essa rede. Tal rede cumpre a função de restringir as áreas queimadas e dificultar o avanço do fogo para maiores extensões, embora esteja também relacionada com a ignição de algumas queimadas por meio de acidentes.

O presente trabalho levou em consideração somente as cicatrizes de queimadas visíveis ao longo dos anos nas imagens LANDSAT e ResourceSat para a montagem da base considerada como referência. Embora não tenham sido mapeadas as áreas queimadas utilizando-se do sinal de rebrota da vegetação (Pereira \& França, 2005; França et al., 2007), acredita-se que as inclusões dessas novas áreas poderiam contribuir para um aumento nos níveis de acurácia na comparação com os dados MODIS, visto que as justificativas dos baixos níveis de acurácia em alguns anos estudados foram a indisponibilidade de imagens LANDSAT ou ResourceSat em data posterior e próxima à ocorrência de queimada e também a cobertura de nuvens. Com isso, as áreas não mapeadas em um determinado ano, por conta dos fatores acima citados, poderiam ser mapeadas a partir do sinal de rebrota em imagens do ano seguinte, aumentando a área queimada mapeada na base de referência e possibilitando mostrar melhores índices de acurácia. 


\section{CONCLUSÕES}

A metodologia utilizada mostrou potencialidade para o mapeamento temporal das ocorrências de queimadas. A filtragem por Savitzky-Golay garantiu a eliminação dos ruídos e a suavização das séries temporais. Este procedimento permitiu a preservação dos picos de valores mínimos nas séries temporais com grande importância para o mapeamento dos eventos de queimadas, uma vez que a ação do fogo ocasiona uma queda repentina dos valores NBR.

A normalização dos dados com a utilização da Média foi de grande importância, pois permitiu a definição de um único limiar capaz de separar as áreas queimadas independente do ambiente observado, garantindo uma mesma relação sinal/ruído que não se verifica na diferença sazonal. A aplicação dessa normalização se mostra bastante interessante ao se analisar áreas no Cerrado, onde as distinções das fitofisionomias são consideráveis. O índice nmNBR permitiu maior destaque das áreas queimadas, facilitando e tornando mais confiável o mapeamento dessas ocorrências em séries temporais. Na definição dos melhores valores limite para corte foram obtidos altos níveis de acurácia dos índices Kappa (77,482 em 2005; 72,392 em 2010 e 95,519 em 2014) e Overall (89,141 em 2005; 94,842 em 2010 e 99,295 em 2014). O mapeamento por meio da aplicação do melhor limiar permitiu a individualização das áreas queimadas, que foram comparadas com os dados de referência.

A comparação entre os mapeamentos automatizados das séries temporais MODIS com as interpretações visuais a partir dos sensores de melhor resolução demonstraram algumas divergências significativas no mapeamento. As diferenças encontradas proporcionam sempre um aumento de ocorrência em imagens MODIS por conta, principalmente, da subestimativa da classificação visual devido a falta de dados provenientes da cobertura de nuvens e grandes intervalos sem recobrimento de imagens. De um modo geral, a metodologia se mostrou uma forma bastante completa e robusta na análise de queimadas em ambientes de Cerrado. Embora existam algumas diferenças como as citadas acima, os dados MODIS, LANDSAT e Resourcesat se complementam aperfeiçoando a análise dinâmica de eventos de fogo.

A análise dos resultados permite notar uma nova dinâmica do fogo na região, diferente da encontrada por França \& Setzer (1997), onde se observavam extensas ocorrências de queimadas em um intervalo de 3 anos. Os dados demonstram que a nova 
estratégia de manejo do fogo utilizada pelo parque, com a manutenção de aceiros, implantação de brigada de incêndios e reformulação do plano de manejo mostrou-se bastante efetiva, corroborando com os resultados encontrados por França et al. (2007).

Levando em consideração a existência desse fenômeno independente da ação antrópica, outras unidades de conservação deveriam valer-se da experiência do Parque Nacional das Emas e incorporar estratégias semelhantes para o manejo do fogo. Certamente pesquisas como esta, que visam à análise espaço-temporal das queimadas, podem dar contribuições fundamentais para o planejamento e gestão de áreas naturais, além da possibilidade de embasamento em ações de preservação e fiscalização de áreas no Cerrado. 


\section{REFERÊNCIAS BIBLIOGRÁFICAS}

ALMEIDA FILHO, R., SHIMABUKURO, Y. E., 2004, Monitoring biomass burning in the Brazilian Amazônia. International Journal of Remote Sensing, 25(24), pp. 5537-5542.

AMORIM, P.K. \& BATALHA, M.A., 2007. Soil-vegetation relationships in hyperseasonal cerrado, seasonal cerrado, and wet grassland in Emas National Park (central Brazil). Acta Oecologica, 32, pp. 319-327.

ARAÚJO, F. M., FERREIRA, L. G., ARANTES, A. E., 2012, Distribution Patterns of Burned Areas in the Brazilian Biomes: an Analysis Based on Satelite Data for the 20022010 Period. Remote Sensing, 4, pp. 1929 - 1946.

BARKER, J.L., HARDEN, M. K., ANUTA, E. A., SMID, J. E., HOUGT, D., 1992, MODIS Spectral Sensitivy Study: Requirements and Characterization. Washington: NASA, 84.

BOSCHETTI, L., ROY, D. P., BARBOSA, P., BOCA, R., JUSTICE, C. 2008a. A MODIS assessment of the summer 2007 extent burned in Greece. International Journal of Remote Sensing, 29, pp. 2433-2436.

BOSCHETTI, L., ROY, D., JUSTICE, C. 2008b. Using NASA's world wind virtual globe for interactive visualization of the global MODIS burned area product. International Journal of Remote Sensing, 29, pp. 3067-3072.

BRADLEY, A. V., GERARD, F. F., BARBIER, N., WEEDONS, G. P., ANDERSON, L. O., HUNTINGFORD, C., ARAGÃO, L. E. O. C., ZELAZOWSKI, P., ARAI, E., 2011, Relationships between phenology, radiation and precipitation in the Amazon Region. Global Change Biology, 17, pp. 2245 - 2260.

CANSLER, C.A., McKENZIE, D., 2012, How Robust Are Burn Severity Indices When Applied in a New Region? Evaluation of Alternate Field-Based and Remote Sensing Methods. Remote Sensing. 4, pp. 456-483.

CARVAlHo JÚNIOR, O. A., HERMUCHE, P.M., GUIMARÃES, R.F. 2006, Identificação Regional da Floresta Estacional Decidual na Bacia do Rio Paranã a partir da Análise Multitemporal de Imagens Modis. Revista Brasileira de Geofísica. 24(3), pp. 319-332. 
CARVALHO JÚNIOR, O. A., COUTO JÚNIOR, A. F., SILVA, N. C., MARTINS, E. S., CARVAlHO, A. P. F., GOMES, R. A. T., 2009, Avaliação dos Classificadores Espectrais de Mínima Distância Euclidiana e Spectral Correlation Mapper em Séries Temporais NDVI-MODIS no Campo de Instrução Militar de Formosa (GO). Revista Brasileira de Cartografia, 61(04), pp. 399 - 412.

CARVALHO JÚNIOR, O. A., GUIMARÃES, R. F., SILVA, C. R., GOMES, R. A. T., 2015, Standardized Time-Series and Interannual Phenological Deviation: New Techniques for Burned-Area Detection Using Long-Term MODIS-NBR Dataset. 2015, Remote Sensing. 7, pp. 6950-6985.

CARVALHO JÚNIOR, O. A., SILVA, N. C., CARVALHO, A. P. F., COUTO JÚNIOR, A. F., SILVA, C. R., SHIMABUKURO, Y. E., GUIMARÃES, R. F., GOMES, R. A. T., 2012, Combining noise-adjusted Principal Components Transform and Median Filter techniques for denoising MODIS temporal signatures. Revista Brasileira de Geofísica, 30(2), pp. $147-157$.

CERRI, C. C., MAIA, S . M. F., GALDOS, M . V., CERRI, C. E. P., FEIGL, B. J., BERNOUX, M., 2009, Brazilian greenhouse gas emissions: the importance of agriculture and livestock. Scientia Agricola, Piracicaba. 66(6), pp. 831 - 843.

CHEN, J., JÖNSSON, P., TAMURA, M., GU, Z., MATSUSHITA, B., EKLUNDH, L., 2004, A simple method for reconstructing a high-quality NDVI time-series data set based on the Savitzky-Golay filter. Remote Sensing of Environment, 91, pp. 332-344.

CHUVIECO, E., 1999, Measuring changes in landscape pattern from sattelite images: shor-term effects of FIRE on spatial diversity. International Journal of Remote Sensing, 20(12), pp. 2331-2346.

CHUVIECO, E., OPAZO, S., SIONE, W., DEL VALlE, H., ANAYA, J., DI BELLA, C. CRUZ, I., MANZO, L., LÓPEZ, G., MARI, N., GONZÁleZ-AlONSO, F., MORELLI, F., SETZER, A., CSISZAR, I., KANPANDEGI, J.A., BASTARRICA, A., LIBONATI, R., 2008, Global Burned-land Estimation in Latin America Using MODIS Composite Data. Ecological Applications, 18(1), pp. 64-79. 
CHUVIECO, E., VENTURA, G., MARTIN, M. P., GOMEZ, I. 2005. Assessment of multitemporal compositing techniques of MODIS and AVHRR images for burned land mapping. Remote Sensing of Environment, 94, pp. 450-462.

CONGALTON, R.; GREEN, K. 1999, Assessing the Accuracy of Remotely Sensed Data: Principles and Practices; CRC/Lewis Press: Boca Raton, FL, USA.

COPPIN, P., JONCKHEERE, I., NACKAERTS, K., MUYS, B., 2004, Digital change detection methods in ecosystem monitoring: a review. International Journal of Remote Sensing, 25(9), pp. 1565-1596.

COUTO JÚNIOR, A. F., CARVALHO JÚNIOR, O. A., MARTINS, E. S., IMAÑA ENCINAS, J., 2007, Identificação das Assinaturas Temporais NDVI das Principais Fisionomias da Região do Ecomuseu do Cerrado. Espaço e Geografia, (UnB), Brasília, 10(1), pp. 173-189.

COUTO JÚNIOR, A. F., CARVALHO JÚNIOR, O. A., MARTINS, E. S., SANTANA, O. A., SOUZA, V. V., ENCINAS, J. I., 2011, Tratamento de Ruídos e Caracterização de Fisionomias do Cerrado Utilizando Séries Temporais do Sensor MODIS. Revista Árvore. Viçosa - MG, 35(3), pp. 699-705.

DALDEGAN, G. A., CARVALHO JR., O. A., GUIMARÃES, R. F., GOMES, R. A. T., RIBEIRO, F. F., McMANUS, C., 2014, Spatial patterns of fire recurrence using remote sensing and GIS in the brasilian savana: Serra do Tombador Nature Reserve, Brasil. Remote Sensing. 6, pp. 9873-9894.

DIAS, B. F. S., 2006, Degradação ambiental: os impactos do fogo sobre a biodiversidade do cerrado. In: Gary, I.; BECKER, B.K. Dimensões humanas da biodiversidade. Petrópolis. Vozes. pp. 187-260.

DIAZ-DELGADO, D., LLORET, F., PONS, X., 2003, Influence of fire severity on plant regeneration by means of remote sensing imagery. International Journal of Remote Sensing. 24(8), pp. 1751-1763.

EITEN G., 1972, The Cerrado Vegetation of Brazil. Botanical Review, 38(2), pp. 201341. 
EITEN, G., 1985, Vegetação. In: Novaes Pinto, M. ed. Cerrado: caracterização, ocupação e perspectivas. 2 ed. Brasília: Editora Universidade de Brasília, pp.17-73.

EPTING, J., VERB YL, D., SORBEL, B. 2005, Evaluation of remotely sensed indices for assessing burn severity in interior Alaska using Landsat TM and ETM+ . Remote Sensing of Environment, 96, pp. 228-239.

FANG, L., YANG, J., 2014, Atmospheric effects on the performance and threshold extrapolation of multi-temporal Landsat derived dNBR for burn severity assessment. International Journal of Applied Earth Observation and Geoinformation. 33, pp. 10-20.

FRANÇA \& RIBEIRO, 2008, Mapeamento de queimadas no Parque Nacional da Serra do Cipó e na Área de Proteção Ambiental Morro da Pedreira, MG: 1984-2007 - ICMBio, pp. 75.

FRANÇA, H., RAMOS NETO, M. B., SETZER, A., 2007. O fogo no Parque Nacional das Emas. MMA, Série Biodiversidade, 27.

FRANÇA, H., SETZER, A. 1999. A história do fogo no Parque das Emas. Ciência hoje, 26(153), pp. 69-73.

FRANÇA, H., SETZER, A., 1997. Regime de queimadas no Parque Nacional das Emas, GO: 1973-1995. Relatório de Pesquisa FAPESP.

FRANÇA, H.; PEREIRA, A.; PINTO JR., O.; FERNANDES, W.A.; GÓMEZ, R.P.S., 2004. Ocorrências de raios e queimadas naturais no Parque Nacional das Emas, GO, na estação chuvosa de 2002-2003. In: Congresso Brasileiro de Unidades de Conservação, 4, 17-21/outubro/2004, Curitiba. Anais. Curitiba: Fundação O Boticário de Proteção à Natureza / Rede Nacional Pró-Unidades de Conservação.

GIGLIO, LG. R., VAN DER WERF, J. T., RANDERSON, G. J. COLLATZ, KASIBHATLA. P. S., 2006, Global estimation of burned area using MODIS active fire observations. Atmospheric Chemistry and Physics. 6, pp. 957- 974.

GOMES, L., MARACAHIPES, L., MARIMON, B. S., REIS, S. M., ELIAS, F., SANTOS, L. M., MARIMON JUNIOR, B. H., LENZA, E., 2014, Post-fire recovery of savana vegetation from rocky outrcrops. Flora. 209, pp. 201-208. 
IBAMA, 2004, Plano de Manejo do Parque Nacional das Emas/GO-MS-MT. Ministério do Meio Ambiente - MMA, Brasília.

JAISWAL, R.K., MUKHERJEE, S., RAJU, K.D., SAXENA, R., 2002, Forest fire risk zone mapping from satellite imagery and GIS. International Journal of Applied Earth Observation and Geoinformation 4 (1), pp. 1-10.

JUSTICE, C. O., TOWNSHEND, J. R. G., VERMOTE, E. F., MASUOKA, E., WOLFE, R. E., SALEOUS, N., ROY, D. P., MORISETE, J. T., 2002, An overview of MODIS Land data processing and product status. In: Remote Sensing of Environment. 83, pp. 3 15 .

KASISCHKE, E.S.; FRENCH, N.H.; HARRELL, P.; CHRISTENSEN JR, N.L.; USTIN, S.L.; BARRY, D. 1993. Monitoring of wildfires in boreal forests using large area AVHRR NDVI composite image data. Remote Sensing of Environment. 45(1), pp. 61-71.

KEY, C.H.; BENSON, N.C. 1999. The Normalized Burn Ratio, a Landsat TM radiometric index for burn severity incorporating multi-temporal differencing. US Geological Survey, Unpublished manuscript.

KINOSHITA, A. M., HOGUE, T. S., 2011, Spatial and temporal controls on post-fire hydrologic recovery in Southern California watersheds. Catena. 87, pp. 240-252.

KOBAYASHI, H., DYE, D. G., 2005, Atmospheric conditions for monitoring the longterm vegetation dynamics in the Amazon using normalized difference vegetation index. Remote Sensing of Environment. 97, pp. 519-525.

LANDIS J.R., KOCH G.G., 1977, The measurement of observer agreement for categorical data. Biometrics. 33, pp. 159-174.

LARIS, P. S., 2005, Spatiotemporal problems with detecting and mapping mosaic fire regimes with coarse-resolution satellite data in savanna environments. Remote Sensing of Environment. 99, pp. 412-424.

LibOnAti, R., DaCAMARA, C. C., PEREIRA, J. M. C., PERES, L. F., 2010, Retrieving middle-infrared reflectance for burned area mapping in tropical environments using MODIS. Remote Sensing of Environment. 114, pp. 831-843. 
LOBODA, T.; O’NEAL, K.J.; CSISZAR, I. 2007, Regionally adaptable dNBR-based algorithm for burned area mapping from MODIS data. Remote Sensing of Environment. 109. pp. 429-442.

LOZANO, F. J., SUAREZ-SEOANE, S., LUIS, E. 2007, Assessment of several spectral indices derived from multi-temporal landsat data for fire occurrence probability modelling. Remote Sensing of Environment. 107. pp. 533-544.

MAEDA, E. E., ARCOVERDE, G.F.B., PELlIKKA, P.K.E., SHIMABUKURO, Y.E., 2011, Fire risk assessment in the Brazilian Amazon using MODIS imagery and change vector analysis. Applied Geography. 31, pp. 76-84.

MAEDA, E.E., FORMAGGIO, A.R., SHIMABUKURO, Y.E., ARCOVERDE, G.F.B., HANSEN, M.C., 2009, Predicting forest fire in the Brazilian Amazon using MODIS imagery and artificial neural networks. International Journal of Applied Earth Observation and Geoinformation. 11, pp. 265-272.

MEDEIROS, M. B.; MIRANDA, H. S. 2005, Mortalidade pós-fogo em espécies lenhosas de campo-sujo submetido a três queimadas prescritas anuais. Acta Botanica Brasilica. 19, pp. 493-500.

MENESES, P.R., ALMEIDA, T. de. 2012, Introdução ao Processamento de Imagens de Sensoriamento Remoto. Brasília: UnB/CNPq, 1.

MILLER, J. D., THODE, A. E., 2007, Quantifying burn severity in a heterogeneous landscape with a relative version of the delta Normalized Burn Ratio (dNBR). Remote Sensing of Environment. 109, pp. 66-80.

MIRANDA, H.S., BUSTAMANTE, M.M.C., MIRANDA, A.C., 2002, The fire factor. In: OLIVEIRA, P.S., MARQUIS, R.J. The cerrados of Brazil: ecology and natural history of a neotropical savanna. New York, Columbia University Press, pp. 51-68.

PAUlA E Silva, F., CHANG, H. K., CAETANO-CHANG, M. R., 2003, Perfis de referência do Grupo Bauru (K) no Estado de São Paulo. Revista Geociências UNESP. São Paulo. 22, p. 21-32.

PEREIRA, A., \& FRANÇA, H., 2005. Identificação de queimadas naturais ocorridas no período chuvoso de 2003-2004 no Parque Nacional das Emas, Brasil, por meio de 
imagens dos sensores do satélite CBERS-2. Anais XII Simpósio Brasileiro de Sensoriamento Remoto, Goiânia, Brasil, pp. 16-21.

PETROPOULOS, G.P., VADREVU, K.P., XANTHOPOULOS, G., KARANTOUNIAS, G., SCHOLZE, M., 2010, A comparison of spectral angle mapper and artificial neural network classifiers combined with Landsat TM imagery analysis for obtaining burnt area mapping. Sensors. 10, pp. 1967-1985.

PIVEllO, V. R., COUTINHO, L. M., 1992, Transfer of Macro-Nutrients to the Atmosphere during Experimental Burnings in an Open Cerrado (Brazilian Savanna). Journal of Tropical Ecology. 8(4), pp. 487-49.

RAMOS NETO, M.B. 2000, O Parque Nacional das Emas (GO) e o fogo: implicações para a conservação biológica. São Paulo, Tese (Doutorado) - Instituto de Biociências da Universidade de São Paulo. p. 159.

RATTER, J.A., RIBEIRO, J.F., BRIDGEWATER, S., 1997, The Brazilian Cerrado Vegetation and Threats to Its Biodiversity. Annals of Botany. 80, pp. 223-230.

ROCHA, A.F. (Org.). 2003, A defesa dos direitos socioambientais no judiciário. São Paulo: ISA. pp. 313-380.

ROUSE, J.W, HAAS, R.H., SCHEEL, J.A., AND DEERING, D.W., 1974, Monitoring Vegetation Systems in the Great Plains with ERTS. Proceedings, 3rd Earth Resource Technology Satellite (ERTS) Symposium, 1, pp. 48-62.

ROY, D. P., JIN, Y., LEWIS, P. E., JUSTICE, C. O., 2005, Prototyping a global algorithm for systematic fire affected area mapping using MODIS time series data. Remote Sensing of Environment, 97, pp. 137-162.

SALOMONSON, V. V., TOLL, D. L., 1991, Execution phase (C/D) spectral band characteristics of the EOS moderate resolution imaging spectrometer-nadir (MODIS-N) facility instrument. In: Advances in Space Research, 11(3), pp. 231-236.

SAMPAIO, C. da S., 2007, Abordagem metodológica baseada nos dados multitemporais MODIS EVI/NDVI para classificação da cobertura vegetal na região do Parque Nacional 
da Chapada dos Veadeiros/GO. Dissertação (Mestrado em Geografia) - Universidade de Brasília, Brasília. p. 73.

SANO E.E., BARCELLOS A.O., BEZERRA H.S., 2001, Assessing the spatial distribution of cultivated pastures in the Brazilian savanna. Pasturas Tropicales, 22(3) pp. $2-15$.

SAVITZKY, A., GOLAY, M. J. E., 1964, Smoothing and differentiation of data by simplified least squares procedures. Analytical Chemistry, 36, 1627- 1639.

SCHROEDER, W., PRINS, E., GIGLIO, L., CSISZAR, I., SCHMIDT, C., MORISETTE, J., MORTON, D., 2008, Validation of GOES and MODIS active fire detection products using ASTER and ETM + data. Remote Sensing of Environment. 112, pp. 2711-2726.

SETZER, A., MORELLI, F., RIVERA-LOMBARD, R. 2007, Estimativa quinzenal de áreas queimadas. In: RUDORFF, B. F. T.; SHIMABUKURO, Y. E.; CEBALLHOS, J. C. Sensor Modis e suas Aplicações Ambientas no Brasil. São José dos Campos: Parêntese, pp. 448.

SHIMABUKURO, Y. E.; DOS SANTOS, J. R.; LEE, D.C.L.; DA COSTA PEREIRA, M. 1991. Dados sensoriados no monitoramento e avaliação de áreas queimadas: o caso do Parque Nacional de Emas (GO). Pesquisa Agropecuária Brasileira, 26(10), pp. 15891598.

SILVA, J.M.N., SÁ, A.C.L., PEREIRA, J.M.C., 2005, Comparison of burned area estimates derived from SPOT-VEGETATION and Landsat ETM+ data in Africa: Influence of spatial pattern and vegetation type. Remote Sensing of Environment. 96, pp. $188-201$.

SOARES, P.C.; LANDIM, P.M.B.; FÚLFARO, V.J.; SOBREIRO NETO, A.F., 1980, Ensaio de caracterização estratigráfica do Cretáceo no Estado de São Paulo: Grupo Bauru. Revista Brasileira de Geociências, 10(3), pp. 177-185.

STAVROULAKIS, P.I., LIATSIS, P., TIPPING, N., CRADDOCK, P., 2013, Evaluation and optimization of the Savitzky-Golay smoothing filter for noise reduction in thin film interference signal analysis. Proceedings of SPIE. $\mathbf{8 8 4 2}$. 
UNESCO, United Nations Educational, Scientific, and Cultural Organization, 2001, Cerrado protected areas: Chapada dos Veadeiros and Emas National Parks. Paris. Available from: http://http://whc.unesco.org/en/list/1035. Acessed: 17/06/2015.

VAN WAGTENDONK, J. W., ROOT, R. R., KEY, C. H., 2004, Comparison of AVIRIS and Landsat ETM+ detection capabilities for burn severity. Remote Sensing of Environment, 92, pp. 397-408.

VERAVERBEKE, S., HOOK, S., HULLEY, G., 2012, An alternative spectral index for rapid fire severity assessments. Remote Sensing of Environment. 123. pp. 72-80.

VERAVERBEKE, S., LHERMITTE, S., VERSTRAETEN, W. W., GOOSSENS, R., 2010, The temporal dimension of differenced Normalized Burn Ratio (dNBR) fire/burn severity stuydies: The case of the large 2007 Peloponnese wildfires in Greece. Remote Sensing of Environment. 114, pp. 2548-2563.

VERAVERBEKE, S., HARRIS, S., HOOK, S., 2011, Evaluating spectral indices for burned area discrimination using MODIS/ASTER (MASTER) airborne simulator data. Remote Sens. Environ. 115(10), pp. 2702-2709.

VERBESSELT, J., JÖNSSON P., LHERMITTE S., JONCKHEERE, I., VAN AARDT J., COPPIN, P., 2006, Relating time-series of meteorological and remote sensing indices by extraction of seasonality metrics to monitor vegetation moisture dynamics. Signal and Image Processing for Remote Sensing. pp. 153-172.

WARDLOW, B. D., EGBERT, S. L., 2008, Large-area crop mapping using time-series MODIS 250 m NDVI data: An assessment for the U.S. Central Great Plain. Remote Sensing of Environment. 112, pp. 1096 - 1116.

WOLF, R.E., NISHIHAMA, M., FLEIG, A.J., KUYPER, J.A., ROY, D. P., STOREY, J.C., PATT, F. S., 2002, Achieving Sub-Pixel geolocation accuracy in Support of MODIS Land Science. Remote Sensing of Environment, 83(1-2), pp. 31-49.

ZHANG, X., 2015, Reconstruction of a complete global time series of daily vegetation index trajectory from long-term AVHRR data. Remote Sensing of Environment. 156, pp. 457-472. 
ZHAO, H., YANG, Z., DI, L., LI, L., ZHU, H., 2009, Crop phenology date estimation based on NDVI derived from the reconstructed MODIS daily surface reflectance data. Geoinformatics. 